\title{
Bulletin d'histoire de la Belgique (1962-1963)
}

Jean Dhondt, Wilfrid Brulez, Jan Craeybeckx, Paul Deprez, Walter Prevenier, S.

Scholliers, D. Van der Veeghde, Romain Van Eenoo, J. Verhelst, Adriaan Verhulst, U. Vermeulen

\section{Citer ce document / Cite this document :}

Dhondt Jean, Brulez Wilfrid, Craeybeckx Jan, Deprez Paul, Prevenier Walter, Scholliers S., Van der Veeghde D., Van Eenoo Romain, Verhelst J., Verhulst Adriaan, Vermeulen U. Bulletin d'histoire de la Belgique (1962-1963). In: Revue du Nord, tome 46, n¹81, Avril-juin 1964. pp. 253-302;

doi : https://doi.org/10.3406/rnord.1964.2501

https://www.persee.fr/doc/rnord_0035-2624_1964_num_46_181_2501

Fichier pdf généré le 07/04/2018 


\section{Chronique}

\section{BULLETIN D'HISTOIRE DE BELGIQUE 1962-1963}

par J. Dhond, professeur à l'Université de Gand; W. BRuLEZ, chargé de recherches du Fonds National de la Recherche Scientifique; J. CRAEYBECKX, chargé de cours à l' Université de Bruxelles; P. DEPREz, chargé de cours à l'Institut National de Diffusion Culturelle; W. Prevenier, chef de travaux à la Faculté de Philosophie et Lettres de l'Université de Gand; St. SCHOLliers, assistant à l'Université de Gand; D. VAN DER VEEGHDE, conservateur aux Archives Générales du Royaume; R. VAN EENOO, assistant à la Faculté de Philosophie et Lettres de l'Université de Gand; J. VERHELST, assistant à la Faculté de Philosophie et Lettres; A. VeRHULST, chargé de cours à la Faculté de Philosophie et Lettres; U. Vermeulen, assistant à la Faculté de Philosophie et Lettres de l' Université de Gand.

Le 23 décembre 1862 naquit à Verviers le grand historien belge Henri Pirenne. L'année 1962 a été marquée par plusieurs manifestations commémoratives. A Bruxelles, les Académies réunies ont organisé une séance le 19 décembre, en présence du Roi et de la Reine et sous la présidence du ministre de l'Education Nationale V. Larock. Trois discours furent prononcés par les professeurs Van Werveke et Vercauteren, élèves de Pirenne et par le délégué de l'Institut de France, Ch. Samaran. M. Van Werveke traita particulièrement de l'historien national et de la personnalité du maître, $M$. Vercauteren de son œuvre en général '. A l'Université de Gand, une commémoration plus intime a réuni les autorités académiques, les anciens élèves et une multitude d'étudiants, dans le grand auditoire de la Faculté le 11 décembre. Là aussi le professeur Van Werveke retraça la vie de son maître, en mettant en lumière ses travaux d'histoire nationale et économique. Ensuite le professeur F.-L. Ganshof évoqua les études de Pirenne sur l'histoire générale du moyen âge, l'histoire des villes, et le problème de la transition de l'antiquité au moyen âge (Mahomet et Charlemagne). Avec une profonde émotion, il traça enfin un portrait vivant de Pirenne, professeur et homme de cœur ${ }^{2}$. Une autre manifestation eut lieu à Verviers, ville natale de l'historien. Deux expositions sur sa vie et ses œuvres ont rappelé son souvenir, l'une aux Archives Générales du Royaume à Bruxelles, l'autre à la Faculté de Philosophie et Lettres de

\footnotetext{
1. Les textes des discours ont été publiés dans le Bulletin de la Classe des Lettres et des Sciences Morales et Politiques, de l'Académie Royale de Belgique, $5^{\circ}$ série, XLIX, 1953, 1.

2. Ces discours se trouvent dans la revue de l'Université de Gand, De Brug, t. 7, 1963, pp. 3-25. Un passage du texte que le prof. Ganshof, trop ému, n’a pu prononcer, est reproduit dans une note de la page 25 .
} 
Gand. Dans un des séminaires d'Histoire de cette faculté un portrait a par ailleurs été inauguré.

En rapport avec "l'année Pirenne » nous devons encore mentionner la brillante étude du professeur $\mathbf{H}$. Van Werveke sur le rôle que Pirenne a joué dans l'évolution de notre science historique depuis le début de sa carrière jusqu'en $1962^{3}$. Il y montre le rayonnement direct et indirect des idées du maître. Si beaucoup de ses ouvres ont vieilli, il suffit souvent de faire quelques retouches pour que l'image reste valable dans ses grands traits. Presque toute la production historique contemporaine s'intègre facilement dans le cadre de la synthèse que Pirenne a élaborée.

Dans la collection «Que sais-je ? », J. Dhondt a écrit une « Histoire de la Belgique $~^{4}$. On connaît le format réduit et l'extrême concision qui caractérise cette collection. L'historien est donc amené à choisir ce qui lui paraît le plus significatif dans l'évolution qu'il retrace et à constituer les cadres qui lui paraissent les mieux adaptés à son sujet. On constatera que l'auteur commence son exposé à la veille de l'époque bourguignonne et l'adapte autant que possible aux phases de l'évolution sociale.

Par ailleurs ${ }^{5}$ en revenant à un sujet qui lui est particulièrement cher : l'importance de l'Ardenne carolingienne, M. F. Rousseau nous donne le grand espoir de voir bientôt paraître une seconde édition de son ouvrage capital sur la Meuse et le Pays Mosan publié en 1930. L'article est un rapide aperçu historique de l'importance de la région du point de vue économique, stratégique, religieux et culturel. Deux annexes sur les villas de chasse et le réseau routier complètent cette alerte synthèse.

Parmi les instruments bibliographiques, il en est un, bien précieux et rarement utilisé, c'est le rapport du jury du « Concours Quinquennal d'histoire nationale ». Tous les cinq ans, comme l'indique le titre, un prix d'histoire nationale est décerné. Traditionnellement, le jury passe en revue, dans son rapport, l'essentiel de la production historique de la période. Mais pourquoi se sert-on si peu de cet instrument? En fait, parce qu'il est peu accessible. Il est publié au « Moniteur Belge » à une date tellement postérieure à l'époque traitée que plus personne ne pense à compulser le Moniteur à cette date. Par exemple, le rapport sur le prix de la période 1956-60 a été publié dans le Moniteur du 7 novembre 1963. Il est vrai qu'un certain nombre d'exemplaires sont tirés à part et diffusés je ne sais exactement comment (les membres du jury en obtiennent quelques-uns et je crois que le département de l'Enseignement Supérieur l'envoie à certaines personnalités). Mais il est clair qu'une fois la distribution faite, il est pratiquement impossible de se le procurer.

C'est dommage, car au total ces rapports sont quelquefois très riches. Cela tient en premier lieu à la personnalité du secrétaire. Pour la période 1956-60, ce rapport vient de sortir de presse et je le crois

3. H. VAN WRRVEKe, De geschiedschrijving in de eeuw na Henri Pirenne's geboorte 1862-1962. Gedenkschriften van de Oudheidkundige Kring van het land van Dendermonde, 1963, 14 pages.

4. J. DHONDT, Histoire de la Belgique, Paris, 1963, (Que sais-ie, $n^{\circ} 319$ ).

5. F. Rousseav, Les carolingiens et l'Ardenne. Bull. Acad. 5e série, t. 48, 1962, pp. 187-221. 
le meilleur qui ait été rédigé depuis vingt ans. Il est l'œuvre de $\mathbf{M}$. J. Ruwet, professeur à Louvain. Ce qui distingue ce rapport des précédents c'est qu'il débute par un aperçu sur l'activité d'un certain nombre d'organismes historiques et qu'il va un peu au-delà de son objectif théorique, puisqu'il cite des travaux relatifs à l'histoire de Belgique dont quelquesuns dus à des auteurs étrangers qui en principe ne devaient pas prendre place dans un exposé limité à ceux qui entraient en compétition pour le prix. Félicitons-nous de cette initiative qui transforme délibérément ce rapport en une bibliographie.

Dans sa série de "répertoires archéologiques », le Centre national de recherches archéologiques vient de publier son tome 3 . Il s'agit d'un répertoire bibliographique des trouvailles archéologiques en Brabant, depuis l'époque du bronze jusqu'aux invasions normandes réalisé par $M$. Desittere ${ }^{6}$. Conçu sur le même modèle que les répertoires précédents (cf. Chronique 1961-62, Revue du Nord, 1963, p. 56). il fournit, commune par commune, une bibliographie critique des trouvailles archéologiques en Brabant, que l'on consultera facilement grâce aux tables topographique et systématique à la fin de l'ouvrage.

\section{LE MOYEN AGE}

\section{Les paysages et les structures}

Il a été rendu compte précédemment (Revue du Nord 1960, pp. 99-100) des travaux de A. Verhulst, chargé de cours à l'Université de Gand, sur la géographie historique de la plaine maritime flamande au moyen âge. Dans le premier article, en langue française, qu'il consacre à ce problème ${ }^{7}$, l'auteur résume les résultats de ses recherches antérieures, fait le point de nos connaissances actuelles et indique les tâches d'une recherche future.

D'autre part un point particulier de la géographie historique de la plaine maritime flamande au moyen âge, à savoir l'évolution de l'estuaire de l'Yser, a été étudié par $\mathbf{R}$. Boterberge, élève de $\mathbf{M}$. Verhulst, dans son mémoire de licence, dont l'essentiel vient d'être publié ${ }^{8}$. La partie la plus originale de cette étude concerne l'évolution paroissiale de la région et l'endiguement de l'estuaire proprement dit par les abbayes de Bourbourg et d'Oudenburg aux XII ${ }^{\mathrm{e}}-\mathrm{XIII}^{\mathrm{e}}$ siècles.

L'étude de E. De Reu sur les tourbières dans les Quatre-Métiers du XII ${ }^{\ominus}$ au XIV siècle $^{9}$, constitue non seulement une contribution importante à la géographie historique de la Flandre zélandaise orientale, mais aussi à l'histoire économique de la Flandre et de la ville de Gand en particulier. Dans l'économie urbaine de Gand, en effet, la possession

6. M. DestrTERE, Bibliografisch repertorium der oudheidkundige vondsten in Brabant (vanaf de bronstijd tot aan de Noormannen). Bruxelles, 1963, 183 p.

7. A. VERHULST, L'évolution géographique de la plaine maritime flamande au moyen âge. Revue de l'Université de Bruxelles, XV, 1962-63, pp. 90-106.

8. R. BOTRRBBRGB, Historische geografie van het overstromingsgebied van de Ijzer in de Middeleeurven. Handel, Maatsch. Gesch. en Oudheidk. Gent, nouvelle série, XVI, 1962, pp. 77-142.

9. $\mathrm{E}$. DE REU, Historisch-geografisch onderzoek betreffende de moergronden in de VierAmbachten tijdens de $12^{\circ}, 13^{\circ}$ en $14^{\circ}$ eeuw. Oudheidk. Kring De Vier Ambachten, te Hulst. Jaarboek 1960-61, pp. 31-69. 
par le patriciat de terres tourbeuses dans la région située au nord de Gand ainsi que la production et la consommation de la tourbe ont joué un rôle important. Le fait que le réseau fluvial au nord de Gand a été créé principalement en fonction du transport de la tourbe vers la ville confirme cette thèse.

L'immense bruyère du Bulskampveld, qui occupait jusqu'au $\mathrm{XIX}^{\circ}$ siècle un vaste territoire de près de 5.000 hectares entre Bruges et Gand, constitue un objet d'étude particulièrement intéressant pour la géographique historique de la Flandre. A cause de sa très grande superficie et de son caractère de terre marginale, elle a été le théâtre de différentes phases de défrichement entre le $\mathrm{XII}^{\circ}$ et le $\mathrm{XIX}^{\circ}$ siècle. Après quelques contributions d'historiens locaux (voir e. a. Chronique 1961-62, p. 77), le géographe L. Daels, assistant à l'Université de Gand, a décrit les étapes du défrichement du Bulskampveld et les transformations du paysage qui en ont été le résultat ${ }^{10}$. Après une introduction géologique l'auteur étudie principalement, à l'aide de sources historiques - cartes et terriers - , la composition changeante de ce "veld » entre le $\mathbf{x v}^{\circ}$ et le xvIII $^{\circ}$ siècle. Si à l'origine le Bulskampveld avait l'aspect d'une immense bruyère entourée d'une zone de bois, où des défrichements locaux avaient eu lieu au $\mathrm{XIII}^{\circ}$ et au $\mathrm{XvI}^{\circ}$ siècle, cette image a changé au $\mathrm{XVIII}^{\circ}$ siècle à la suite d'un mouvement de défrichement que l'on peut qualifier de "rationnel ». La zone boisée, en effet, a été livrée à l'agriculture, tandis que le noyau de bruyères a fait place à une plantation de conifères.

En ce qui concerne l'évolution de l'habitat, l'auteur démontre l'attraction exercée par le Bulskampveld, dont de larges parties étaient utilisées comme communaux : entre le $\mathrm{XV}^{\circ}$ et le XvIrI" siècle, une nuée de petites exploitations se sont concentrées à la lisière méridionale de la bruyère, à cause de leur droit de pâture sur le Bulskampveld.

L'article que le Père $\mathrm{N}$. Huyghebaert consacre à l'histoire de la forêt de Houthulst (entre Ypres et Dixmude), possession de l'abbaye de Corbie ${ }^{11}$, constitue en fait un commentaire pénétrant de deux documents : une charte-notice de Nicolas, abbé de Corbie, de 1096, que l'auteur publie en annexe et une charte du comte de Flandre Thierry d'Alsace de 1151 . Ces documents renseignent principalement sur les droits respectifs de Corbie et du comte de Flandre sur la forêt. Il en ressort que l'abbaye et le comte étaient co-propriétaires de la partie non défrichée de la forêt, tandis que les parties nouvellement défrichées (terrae vacuae) furent mesurées annuellement et divisées en parties égales entre les deux propriétaires.

A la question : l'expansion de l'agriculture des $\mathrm{XII}^{\circ}$ et $\mathrm{XIII}^{\circ}$ siècles est-elle synonyme d'aisance générale pour les paysans? M. Léop. Génicot ${ }^{12}$ répond par la négative (négative très nuancée d'ailleurs) en s'inspirant de trois villages namurois de nature et de structure écono-

10. L. DAELS, Landschapsontwikkeling in en rond het voormalige Bulskampveld (avec résumé français). Revue de la Soc. belge d'Etudes Géographiques XXXI, 1962, pp. 191-228.

11. N. HuYghebaers, La forêt d'Houthulst, possession de Corbie et les comtes de Flandre, dans : Corbie, abbaye royale. Volume du xIII $^{\circ}$ centenaire. Lille, 1963, pp. 231-247.

12. L. Genrcor, L'étendue des exploitations agricoles dans le Comté de Namur à la fin du $X I I I^{\circ}$ siècle. Etudes rurales, 5-6 avril-sept. 1962, pp. 5-31. 
miques différentes mais dont le sol appartient presque exclusivement au même seigneur. Son exposé plein de données précises et de tableaux de répartition et d'évaluation est émaillé de quantité de remarques sur les classes et les institutions du XIII ${ }^{\circ}$ siècle namurois, qui font de cet essai un modèle pour toute enquête de ce genre nouveau.

C'est d'un point de vue tout différent que $M$. G. Despy, chargé de cours à Bruxelles, examine la structure d'un domaine seigneurial brabançon au $\mathrm{Xv}^{\circ}$ siècle : celui de Jauche ${ }^{13}$. Après l'énumération des droits et des revenus et un essai d'évaluation du boni réalisé chaque année, l'auteur se demande si la situation de la terre de Jauche et par conséquent la fortune de la famille est une exception à l'affaiblissement de la noblesse brabançonne des $\mathrm{XIV}^{\circ}$ et $\mathrm{XV}^{\circ}$ siècles.

M. Gaier, jeune chercheur liégeois, s'intéresse, lui, à la campagne ou plat pays de l'ancien diocèse de Liège mais d'un point de vue très particulier : son rôle stratégico-défensif $\mathrm{du} \mathrm{x}^{0}$ au $\mathrm{xv}^{\mathrm{e}}$ siècle ${ }^{14}$. Il explique fort savamment l'existence des églises, des cimetières, des monastères, des villages, des moulins et même des pêcheries à but défensif de même que la construction des fossés et l'importance des rivières. Il montre ainsi le rôle actif du milieu rural dans la résistance aux invasions.

\section{Les villes et leurs habitants. Le commerce et les commerçants}

En un rapide aperçu, qui commence avec les Grecs et va jusqu'au XII $^{\circ}$ siècle, le professeur $\mathbf{F}$. Vercauteren ${ }^{15}$ insiste sur la différence essentielle qui existe entre la notion de cité et celle de commune. La première est un état complet, la seconde un îlot distinct de ce qui l'entoure. Son exposé est illustré d'exemples empruntés notamment à l'histoire de Reims, Arras, Beauvais, Valenciennes, Huy et Cambrai.

Ces dernières années une telle multitude d'études spécialisées ont paru sur les villes des Pays-Bas de la fin du moyen âge et du début des temps modernes, qu'un status quaestionis de cette littérature était tout à fait indiqué. C'est M. J. A. Van Houtte, qui nous le donne ${ }^{16}$.

Une première partie de l'exposé est consacrée aux aspects démographiques : relation entre la population des villes et du plat pays (en Brabant les villes montant de $32 \%$ en 1437 à $37 \%$ en 1496 puis retombant à $34 \%$ en 1526), accroissement au $x^{\circ}$ siècle de la population des grandes villes (Bruxelles, Anvers) et diminution dans les petites et à la campagne, poussée spectaculaire des villes de Hollande entre 1496 et 1514, exemple d'Amsterdam qui triple sa population de 1514 à 1622 , reprise générale au début du $\mathrm{Xvi}^{\circ}$ siècle.

L'auteur analyse ensuite l'évolution de la structure économique

13. G. DESPY, Un domaine seigneurial au bas moyen age : la terre de fauche dans la seconde moitié du $X V^{\text {e }}$ siècle. Le moyen âge, t. 69, 1963, pp. 867-889.

14. C. GAIER, La fonction stratégico-défensive du plat pays au moyen âge dans la région de la Meuse Moyenne. Le moyen âge, t. 69, 1963, pp. 753-771.

15. F. Vercauteren, $D e$ la cité antique à la commune médiévale. Bull. Acad. 5' série, t. 48, 1962, pp. $130-140$.

16. J. A. VAN Houtre, Die Stadte der Niederlande im Ubergang vom Mittelalter zur Neuzeit. Rheinische Vierteljahrsblätter, XXVII, 1962, pp. 50-68. 
des villes : au XIII ${ }^{\mathrm{e}}$ siècle la draperie de la Flandre prévalait mais du $\mathrm{XIV}^{0}$ siècle le Brabant améliorait nettement sa position sur le marché, comme la Hollande au XV $\mathbf{X V}^{\circ}$ siècle. Dans les villes de la Meuse, l'industrie du métal avait une certaine importance, la concurrence étrangère provoquait au XIV siècle une crise générale et la naissance d'une " nouvelle draperie » de moindre qualité, surtout dans les petits centres, qui est à son tour en décadence dès le milieu du $\mathbf{X v}^{\circ}$ siècle. Dans cette cascade

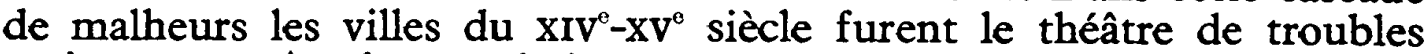
sociaux au sein de populations menacées de chômage et aspirant à obtenir une influence dans le gouvernement urbain par l'intermédiaire du système corporatif, sauf en Hollande où les métiers ont connu beaucoup moins de succès. Pour parer aux crises les villes ont dû chercher le salut dans la spécialisation en produits de luxe ou semi-luxe, telle la production des tapis, des chapeaux et des gants à Anvers.

Dans un troisième chapitre l'auteur aborde l'aspect social de la vie urbaine. Si les conflits des environs de 1477 furent l'œuvre des classes moyennes, au $\mathrm{XVI}^{\mathrm{e}}$ siècle le prolétariat a été à la base de beaucoup de troubles, comme au XIV $^{\circ}$ siècle. La prospérité croissante des entrepreneurs dès la fin du $\mathrm{Xv}^{\circ}$ siècle marchait de pair avec un appauvrissement de la masse des ouvriers. Ce paupérisme du $\mathrm{xvI}^{\circ}$ siècle et la hausse des prix des céréales provoquait les « révoltes de faim》des années 1520-30.

Dans une dernière partie, le professeur Van Houtte s'élève contre cet autre "mythe » de notre historiographie présentant les villes des Pays-Bas comme des démocraties. La gestion urbaine a toujours eu un caractère aristocratique et oligarchique, et les révolutions "démocratiques » ont tenu la majeure partie de la population à l'écart des droits politiques.

C'est à la même conclusion qu'arrive $M$. Van Uytven ${ }^{17}$. En partant d'une analyse quantitative de l'organisation corporative et de ia structure sociale des communes à la fin du moyen âge, il nous démontre que les "anciennes démocraties des Pays-Bas 》n'étaient en fait que des ploutocraties à peine déguisées. Tout au plus le pouvoir était-il partagé entre le patriciat et les corporations représentées par les seuls maîtres. La richesse restait la condition indispensable du succès politique. Ce sont surtout les sources fiscales qui lui ont permis d'indiquer qu'à Louvain, Ninove, Malines, Namur, Courtrai, Bruges et Gand, la partie la plus nombreuse et la moins aisée de la population n'était pas ou fort mal représentée dans le Magistrat urbain.

Mais pour l'histoire des villes l'événement le plus important de 1963 est sûrement la parution du beau livre de M. R. Van Uytven, sur les finances de la ville de Louvain du $\mathrm{XII}^{\mathrm{e}}$ à la fin du Xvi ${ }^{\mathrm{e}}$ siècle ${ }^{18}$. Comparé aux études similaires de ses prédécesseurs, l'ouvrage offre un aspect nouveau et attrayant, car il étudie les finances dans le contexte plus large de l'économie et de la structure sociale de la ville.

\footnotetext{
17. Plutokratie in de oude demokratië̈n der Nederlanden . Handelingen XVI der Kan. Nederl. Maatsch. voor Taal-en Letterkunde en Geschiedenis, 1962, pp. 373-409.

18. R. VAN UYTVEN, Stadsfinanciën en stadsekonomie te Leuven van de XII' tot het einde der XVI' eeuw. Verhandelingen van de Koninklijke Vlaamse Academie voor Wetenschappen, Letteren en Schone Kunsten van Belgiè, Klasse Letteren, ${ }^{\circ}$ 44, Brussel, 1961, XXXII, 723 p.
} 
Dans la première partie (Les finances de la ville), l'auteur a recherché l'origine des finances urbaines en notant qu'en 1378 l'unité des différentes caisses a été réalisée et qu'au $\mathrm{XVI}^{\ominus}$ siècle est apparu le budget extraordinaire pour financer les dépenses spéciales. Les tentatives du prince et du peuple pour obtenir un certain contrôle sur la gestion ont provoqué plusieurs conflits et au $x^{\circ}$ siècle le prince propose un plan d'assainissement. Après avoir expliqué le fonctionnement matériel de la gestion par le conseil de la ville, le large conseil, les commissions et les maîtres de paiement, $\mathbf{M}$. V. U. expose en détail les questions techniques : comptabilité, problèmes du budget, clôture de l'année de compte, image fidèle ou infidèle des comptes, usage de la monnaie de compte. Viennent ensuite les questions de politique financière : immunité du clergé et de l'Université de Louvain, énumération des revenus (domaines, recettes de l'autorité publique, impôts) et des dépenses (ordinaires : aides au duc, salaires, frais de déplacement et administratives, cadeaux ; extraordinaires : travaux publics, frais militaires, etc.), problème des emprunts (rentes à vie et héréditaires). Comme partout en Europe, la ville était constamment en mal d'argent, ses revenus étant peu souples et ses dépenses trop variables. Comme ailleurs, Louvain a lutté contre les immunités.

Dans une deuxième partie, l'auteur esquisse le cadre économique dans lequel ces finances ont évolué. Ce cadre est structuré selon les secteurs de l'économie : l'alimentation, les boissons, les vêtements, les bâtiments et les arts, le transport, le commerce de l'argent. Par sa situation géographique, Louvain a toujours été un carrefour commercial important du Brabant, notamment pour l'exportation de grains vers le Nord. Si, dès le XIII ${ }^{\mathrm{e}}$ siècle la viticulture et le commerce de vin du Rhin y connurent une certaine importance, il faudra recourir à la production de la bière comme moyen de substitution au XIV siècle. L'essor de la draperie se situe dans la période 1275-1340, le déclin qui suivit provoqua des révoltes sociales (épisode de Coutereel en 1360). Dès la fin $\mathrm{du} \mathrm{XIV}^{\mathrm{e}}$ siècle plusieurs industries nouvelles sont florissantes : celles du tapis, du lin, de l'imprimerie et du cuir. Louvain n'a donc pas connu une économie très spécialisée, comme celle des villes flamandes. L'économie y conserve même certains traits agraires. Vingt mille habitants constituent encore un marché intérieur fort honorable à la fin du $\mathrm{Xv}^{\circ}$ siècle, mais ce nombre diminue de moitié cent ans après. Les capitalistes louvanistes s'adaptèrent peu aux techniques nouvelles et se contentèrent bientôt de vivre paisiblement de leurs rentes.

Dans la troisième partie l'étude des prix fait apparaître une nette différence entre les prix des grains et ceux des produits industriels en ce qui concerne leurs fluctuations : à long terme la hausse des produits industriels était très supérieure à celle des grains au $\mathbf{X v}^{\circ}$ siècle ; le contraire apparaît au Xvi $^{\mathbf{e}}$ siècle. Quant aux salaires, les statistiques mettent en valeur leur essor toujours croissant jusqu'en 1474, puis leur tendance à la baisse, qui atteint son minimum dans les années 1575-85.

Dans une dernière partie, $M$. Van Uytven analyse la situation économique et sociale des principales familles de Louvain et leurs propriétés foncières.

En résumé, Louvain a connu un essor jusqu'en 1300, la régression 
s'accentua dans les années 1360-85, un nouvel essor s'amorça vers 1430 , pour faire place à une crise aiguë à la fin $d u x^{\mathrm{e}}$ siècle ; la situation ne s'améliora partiellement que vers le milieu du $\mathrm{XvI}^{\mathrm{e}}$ siècle. La crise la plus aiguë devait cependant sévir à la fin de ce siècle.

L'histoire ancienne de la ville de Bruges a fait l'objet de nombreuses études pendant ces dernières années. La dernière en date, celle de Verhulst, avait mis l'accent sur l'importance des changements intervenus entre le $\mathrm{IX}^{\mathrm{i}}$ et le $\mathrm{XII}^{\mathrm{e}}$ siècle dans les communications par eau entre Bruges et la mer (Le Moyen Age, 1960, pp. 37-63). Ce point de vue vient d'être repris par $A$. Koch dans une étude qui tend toutefois à remettre en question un certain nombre d'opinions généralement admises jusqu'à présent ${ }^{19}$. Une grande partie de son exposé tend, en effet, à démontrer que la «Oude Reie », le cours d'eau séparant le marché du "castrum ", a été, contrairement à ce que l'on croyait, un canal artificiel creusé après le $\mathrm{XI}^{\mathrm{e}}$ siècle et que, par conséquent, l'on ne peut lui attribuer le rôle déterminant dans la fixation du noyau urbain primitif, c'est-à-dire le marché, que l'on lui a toujours reconnu. La démonstration de cette thèse repose principalement sur quelques sondages pédologiques que l'auteur a fait entreprendre le long du lit primitif de la «Oude Reie ». Toutefois, à cause de l'état actuel du sol dans cette partie de la ville, les résultats de cet examen pédologique, d'ailleurs assez minces, ne sont guère convaincants. Cela n'a pas empêché $M$. Koch d'essayer de démontrer que la Lange Reie, le cours d'eau qui se situe, également en direction sud-nord, à l'est de la Oude Reie et donc à l'est du « castrum », aurait été le cours d'eau naturel sur les rives duquel la ville primitive se serait développée aux $\mathrm{IX}^{\mathrm{\theta}}-\mathrm{X}^{\mathrm{e}}$ siècles. L'auteur $\mathrm{n}^{\prime}$ hésite donc pas à situer le noyau urbain primitif autour de l'église disparue de Sainte-Walburge, à laquelle, à cause du vocable, il attribue une certaine signification.

Ces thèses à vrai dire assez hypothétiques n'ont toutefois qu'une portée limitée puisque $M$. Koch admet un déplacement de ce noyau primitif vers l'ouest, donc vers le suburbium traditionnel à côté du marché, à partir du $\mathrm{x}^{\mathrm{e}}$ siècle. Dès ce moment il rejoint les opinions courantes sur le développement topographique de Bruges.

M. H. van der Wee a utilisé la correspondance commerciale des archives Datini de Prato pour décrire une réévaluation monétaire manquée décrétée par le duc Jean sans Peur, en $1407^{20}$. Les lettres des correspondants brugeois de Datini montrent bien les réactions du monde des affaires et les difficultés commerciales provoquées par cette tentative de réforme inspirée uniquement, semble-t-il, par les besoins d'argent du duc.

Aux archives de la ville de Bruges se trouve un document fort important : le Register der Herevaerden de 1338 à 1340, établi afin de déterminer pour chaque quartier de la ville de Bruges le montant des recettes et dépenses des dix expéditions militaires de la période 1338-40. M. J. Verbruggen, professeur à l'Université d'Elisabethville,

19. A.C.F. KocH, Brugge's topografische ontwikkeling tot in de $12^{\circ}$ eeuw. Handel. van het Genootschap Société d'Emulation te Brugge, XCIX, 1962, pp. 5-67.

20. L'échec de la réforme monétaire de 1407 en Flandre vu par les marchands italiens de Bruges. Studi in onore di A. Fanfani, III, 1962, pp. 577-589. 
a exploité ce registre de 343 folios, explicité par des comptes de la ville, pour une étude sur l'armée communale de Bruges de 1338 à 1340 et les noms des hommes en état de porter les armes ${ }^{21}$. La lourde charge du service militaire fut répartie entre les quartiers et les métiers de la ville, au prorata du nombre d'habitants et d'ouvriers. Ainsi on établissait un chiffre pour chaque groupe, qui formait un nombre de base (voud). Selon les cas plusieurs vouden furent mobilisés. D'abord M. V. analyse la composition numérique des contingents, en donnant pour chaque expédition les chiffres pour les poorters et chacun des métiers. Il parvient à un total de 7.234 hommes différents, dont 981 poorters et 6.253 gens de métiers. Il est important de remarquer que le chiffre des habitants valides de $M$. V. est supérieur au chiffre de 6.044 que M. Jos. De Smet avait établi en 1933 sur la base du même document, et qui avait permis d'évaluer la population de Bruges en $1340^{22}$. Il sera donc nécessaire de reviser ce chiffre, tout en tenant compte cependant de la récente critique des nouveaux chiffres de $\mathbf{M}$. Verbruggen par $M$. Wijffels ${ }^{23}$. Dans une deuxième partie l'auteur énumère tous les noms des hommes en état de porter les armes mentionnés dans les registres des heerevaerden, en les classant selon les quartiers et les métiers avec référence aux folios où ils sont cités.

Pour Gand, il convient de citer l'étude de $M$. Gysseling ${ }^{24}$ sur la traduction des privilèges gantois datant de 1237 qui est d'abord et surtout un travail de philologue. Si nous le mentionnons ici, c'est parce que cette série de textes (édités par A.C.F. KocH, Vroeg Middelnederlands ambtelijk proza, dans Fontes Minores Medii Aevi, Groningue, 1960) figure parmi les premiers vestiges de la tradition non littéraire du moyen néerlandais, et cela avec les statuts de la léproserie gantoise de 1236 et le livre des biens de l'abbaye Saint-Bavon d'entre \pm 1210 et \pm 1240 (qui sera prochainement édité par $M$. Gysseling et $\mathrm{A}$. Verhulst). L'article que voici est une excellente addition à l'étude de $\mathbf{M}$. Koch. Gysseling conclut qu'une première rédaction peut être située entre 1218 et 1237 et qu'un rédacteur de 1237 a rassemblé les textes et en a normalisé l'orthographe. Il discute alors en détail le système de l'orthographe de 1237.

L'histoire de l'enseignement dans un centre industriel et commercial comme la ville de Gand du $\mathrm{XII}^{\mathrm{e}}$ au $\mathrm{XIV}^{\mathrm{e}}$ siècle, mériterait une étude approfondie. Depuis longtemps M. Pirenne s'est posé la question de la formation technique des marchands. $M^{\mathrm{me}} M$. H. VoordeckersDeclercq, qui est l'auteur d'une excellente thèse de licence sous la direction du professeur Strubbe à Gand, sur le chapitre de SaintePharailde à Gand, qui sera publiée sous peu, apporte au moins quelques éléments précieux au dossier par une courte, mais très attrayante

21. J. F. VERBRUGGEN, Het gemeenteleger van Brugge van 1338 tot 1340 en de namen van de weerbare mannen, Brussel, 1962, $243 \mathrm{p}$.

22. Jos. DE SMET, L'effectif des milices brugeoises et la population de la ville en 1340. R.B.P.H., XII, 1933, p. 636; JOS. DE SMBT, Het bevolkingsciffer van de grote Vlaamse steden in de middeleeuwen. Ad Harenas, Brugge, p. 90.

23. Compte rendu de C. WIJFFELS dans Tijdschrift voor Geschiedenis, t. LXXVI, 1963, pp. 231-233.

24. M. Gyssel.rNG, De Gentse keurenvertaling van circa 1237. Taal en Tongval, XV, 1963, pp. 23-33. 
étude ${ }^{25}$. Puisque les écoles abbatiales ou capitulaires n'étaient pas adaptées aux besoins et à la mentalité de la bourgeoisie, on voit, dès le $\mathrm{XII}^{\circ}$ siècle la population urbaine essayer d'ériger elle-même, et pour elle-même, des écoles. Cependant le comte de Flandre avait octroyé le monopole de l'enseignement dans la ville de Gand au chapitre de SaintePharailde, qui lui était fort cher, puisqu'il était lié à la chapelle de son castrum. Les grandes abbayes de Saint-Pierre et Saint-Bavon exerçaient également le droit d'enseignement dans leurs territoires respectifs. Contre le monopole de Sainte-Pharailde les bourgeois de Gand se dressaient dès le $\mathrm{xuI}^{\ominus}$ siècle. L'incendie du chapitre en 1178 fournissait une belle occasion à ranimer la lutte. En 1179 Philippe d'Alsace transmet la supervision (regimen scolarum) à un de ses notaires, permettant l'existence d'école laïque à côté de Sainte-Pharaïlde. En 1191, dans la fameuse charte de Mathilde de Portugal, veuve de Philippe d'Alsace, les bourgeois ont su arracher la liberté absolue de l'enseignement. Mais ce droit ne fut guère de longue durée : en 1235 déjà la comtesse Jeanne reconquit son monopole scolaire, qu'elle transmit de nouveau au chapitre de Sainte-Pharailde, en se réservant toutefois le droit de nommer le "magister scolarum 》. Les chartes ultérieures, de 1293, 1295 et 1359 prouvent que cette situation a perduré en tout cas jusqu'au $\mathrm{XIV}^{\circ}$ siècle.

Deux inventaires d'archives de petites villes flamandes, Tielt et Eeklo, viennent d'être publiés, respectivement par A. Wijffels et A. De Vos ${ }^{26}$. Les archives de Tielt, appartenant en majorité à l'époque moderne (XVI ${ }^{\mathrm{e}}$-XVIII ${ }^{\mathrm{e}}$ siècles), concernent principalement l'administration de la ville (population, finances, résolutions, etc.), l'église et la table des Pauvres. Les archives se rapportant à la juridiction, les seigneuries et la cour féodale se trouvent toutefois aux Archives de l'Etat à Bruges et ne sont pas reprises dans cet inventaire.

Par contre l'inventaire des archives d'Eeklo par A. De Vos nous fait connaître un fonds homogène et bien conservé, concernant une petite ville, née en 1240 comme ville-neuve d'une initiative de la comtesse Jeanne de Constantinople, et qui connut à la fin du moyen âge un certain développement urbain grâce à sa draperie.

Dans le Trésor des chartes des comtes d'Artois aux Archives départementales d'Arras sont conservés quelques documents importants de la fin du XIII ${ }^{\mathrm{e}}$ siècle concernant la ville de Calais, qui jusqu'à présent semblent avoir échappé à l'attention des historiens.

Parmi ces documents se trouvent deux séries de bans échevinaux allant de 1293 à 1298. Ces textes viennent d'être publiés par M. Gysseling et $\mathrm{C}$. Wijffels ${ }^{27}$. Le premier des deux auteurs attire l'attention sur les nombreux mots et expressions flamands que contiennent ces bans écrits en latin, ce qui prouve que les clercs de la ville connaissaient encore le flamand et que cette langue devait même être à cette

\footnotetext{
25. M. H. VOORDECKERS-DECLERCQ, De S. Veerlescholen en de schoolstrijd te Gert tot het einde der XIII* ecuw. Collationes Brugenses et Gandevenses, III, 1963, pp. 382-393.

26. A. WiJfrels, Stad Tielt. Inventaris van het Oud Archief Tielt, 1962; IV-108 pages stencilées. A. DE Vos, Stad Eeklo. Inventaris van het Oud Archief. Appelties van het Meetjesland, $\mathrm{n}^{\circ} 13,1962,157 \mathrm{p}$.

27. M. GiJsseling et C. WIJFFELs, Diets in schepenverordeningen van Calais uit het einde der $X I I I^{\circ}$ eeuw. Studia Germanica Gandensia, IV, 1962, pD. 9-30.
} 
époque la langue usuelle de la majorité de la population, puisque le latin et le français étaient les langues écrites officielles.

Cette conclusion est corroborée par l'examen des noms de famille, dont un grand nombre $(955+316)$ se retrouvent dans un rôle établi à l'occasion de l'impôt personnel levé après la révolte de la ville en février 1298, dans le but de payer l'amende de 20.000 livres au comte d'Artois. M. Gysseling et P. Bougard, Directeur des Services d'Archives du Pas-de-Calais, viennent de publier les noms conservés dans ce rôle, accompagnés du montant de l'impôt payé par chaque chef de famille ${ }^{28}$. Dans cette liste alphabétique les auteurs ont également incorporé tous les noms de personnes que d'autres documents calaisiens de la fin du XIII $^{\ominus}$ siècle (un censier du comte d'Artois de 1296, les plus anciens comptes de la ville, etc.) nous ont conservés. En appendice, les auteurs ont groupé les toponymes calaisiens relevés dans ces documents. Parmi ces toponymes un certain nombre se rapportent aux polders des environs de Calais. Le rôle d'impôt peut encore servir à une estimation du chiffre de la population à Calais vers la fin du XIIr ${ }^{e}$ siècle. Calais aurait compté, sur la base de ce document, environ 6.000 habitants.

L'histoire sociale médiévale s'est enrichie d'un élément important grâce à l'étude du chanoine G. Coolen, archiviste de Saint-Omer, sur une grande famille bourgeoise de Saint-Omer: les Sainte-Aldegonde, du XII $^{\circ}$ au XIV ${ }^{\mathrm{e}}$ siècle ${ }^{29}$. C'est une des plus vieilles familles de la ville, dont le nom s'explique du fait que leur demeure se trouvait à l'origine en face de l'église Sainte-Aldegonde. M. Coolen étudie soigneusement les demeures de la famille et illustre son exposé de plusieurs croquis. Au cours du XIII ${ }^{e}$ siècle les Sainte-Aldegonde étaient devenus de grands négociants, spécialisés dans l'importation de laines anglaises. Ils faisaient partie de la Hanse de Saint-Omer. Leur importance économique leur donnait un prestige tel qu'ils ont pu occuper plusieurs postes d'échevins, de mayeurs et de chefs de la Hanse. Avec une continuité éclatante, ils se sont maintenus à des postes de commande. Au XIv siècle cependant leur position s'affaiblit nettement, bien qu'au début du siècle des membres de la famille aient été anoblis. Il est très difficile de discerner clairement les personnages, à cause de l'utilisation fréquente des mêmes prénoms dans cette famille d'une prolifération extraordinaire. M. Coolen note que les Sainte-Aldegonde se sont signalés par un large mécénat en faveur d'institutions religieuses et hospitalières.

L'évolution des léproseries urbaines et rurales en Flandre depuis leur origine au XII ${ }^{\theta}$ siècle, jusqu'à leur disparition, par suite de la diminution de la maladie, aux $\mathbf{X V I}^{\mathrm{i}}$-XVII ${ }^{\mathrm{e}}$ siècles, est un sujet de recherches très riche mais quelque peu négligé au profit de celui des maladies pestilentielles, au caractère épidémique spectaculaire et à la forte influence sur l'évolution démographique et économique. C'est ce que montre la série d'articles consacrés par l'abbé Viaene, de Bruges, aux lépreux et aux léproseries en Flandre pendant le moyen âge ${ }^{30}$. Il s'agit

28. P. Bougard et M. Gijsselng, L'onomastique calaisienne à la fin du $13^{e}$ siècle. Anthroponymica, éd. Instituut voor Naamkunde à Louvain, XIII, 1963, $108 \mathrm{p}$.

29. G. CoOlEN, Les Sainte-Aldegonde, grands bourgeois de Saint-Omer aux XII', XIII' et XIV siècles. Bull. Soc. Antiquaires Morinie, XIX, 1962, pp. 577-608.

30. A. VIAENE, Leprozen en Leprozerijen in Vlaanderen. Collationes Brugenses et Gandavenses, 
surtout d'une introduction au sujet, accompagnée d'un aperçu bibliographique, mentionnant également les principales sources groupées par localité. Le cadre géographique de la Flandre est pris dans le sens le plus large, puisque la Flandre wallonne y figure avec Lille, Saint-Omer, Cambrai, Thérouanne, Aire, Bourbourg, Douai et Orchies. Dans un appendice l'auteur a rassemblé des données au sujet des léproseries de quelques villes de l'Artois, du Brabant, du Hainaut et du Namurois.

Par ailleurs, le Père $N$. Huyghebacrt ${ }^{31}$, dans le but de faire connaître la publication de l'abbé Viaene, en donne une analyse et en discute certains points notamment le statut juridique du lépreux et le caractère religieux ou laïc de l'institution.

Si dans la littérature historique sur la Hanse allemande les données sur la Flandre ne manquent point, on ne disposait toutefois pas, jusqu'ici, d'une vue d'ensemble des relations commerciales entre la Flandre et les régions de l'Europe à l'est de l'Elbe au moyen âge. Le professeur Hans Van Werveke ${ }^{32}$, de l'Université de Gand, vient d'écrire cet aperçu, qui, d'après le titre, se limite à la période de la Hanse mais qui, en réalité, couvre tout le moyen âge du vir ${ }^{\mathrm{e}}$ au $\mathrm{Xv}^{\mathrm{e}}$ siècle. Après un aperçu du développement du commerce actif des Flamands, qui atteignirent vers la fin du $\mathrm{XII}^{\mathrm{e}}$ l'espace baltique et qui, durant cette première période, avaient précédé, dans la partie ouest de la ligne Bruges-Lübeck-Novgorod, les marchands de la Hanse, l'auteur examine les courants commerciaux dans la partie est de cette route, à partir de Lübeck, courants dominés dès l'origine par l'activité des marchands de la Hanse et où le rôle de la Flandre n'a été, par conséquent, qu'un phénomène tardif et passif, bien que très important, à cause de l'exportation des draps.

C'est à la draperie aussi que $M$. A. Joris, chef de travaux à Liège s'intéresse mais par le biais de la culture de la guède ${ }^{33}$. Revenant sur une question étudiée naguère avec minutie pour le Namurois, il jette maintenant les bases d'une enquête plus vaste pour toute la Hesbaye. Il y distingue trois foyers de culture : au centre, près de Saint-Trond (au XIII'), à l'est près de Villers-l'Evêque (au XIV'), à l'ouest près de Jodoigne (aux $\mathrm{XIV}^{\mathrm{e}}$ et $\mathrm{XV}^{\mathrm{e}}$ ). Il insiste aussi sur l'importance du transport par eau et compte pour non négligeable tout le réseau navigable de la Dyle, de la Senne et du Démer.

L'attention des historiens du commerce est par ailleurs attirée par l'étude de $M^{\text {lle }}$ Fanchamps, élève du professeur Vercauteren, sur un tonlieu perçu à la limite du pays de Liège et du Limbourg ${ }^{34}$. La publication d'un acte de 1255 de Waleran IV de Limbourg relatif

VII, 1961, pp. 289-314, 551-561 et VIII, 1962, pp. 122-127. Ces différents articles ont été rassemb!és en une brochure : A. VIAENE, Leprozen en Leprozerijen in het oude graafschas Vlaanderen. Algemene inlciding. Bibliografisch overzicht. Brugge, Association des Guides, 1962, 47 p.

31. N. HuYgheBAert, L'origine ecclésiastique des léproseries en Flandre et dans le Nord de la France. Rev. Hist. Eccl. t. 58, 1963, pp. 848-857.

32. H. VAN WERVEKE, Die Beziehungen Flanderns zu Osteuropa in der Hansezeit. Arbeitsgemeinschaft für Forschung des Landes Nordrhein-Westfalen, Wissenschaftliche Abhandlung, t. 27, Cologne, s. d. [1963].

33. A. Joris, La guède en Hesbaye au moyen age. Le moyen âge, t. 69, 1963, pp. 773-789.

34. M. Fanchamps, Note sur un acte inédit de 1255 concernant le tonlieu levé aux limites de la ville de Liège et du duché de Luxembourg. Bull. Com. roy. d'histoire, t. 129, 1963, pp. 51-66. 
à ce tonlieu lui permet entre autre d'insister sur l'importance de la constitution d'un fief-rente pour se procurer du numéraire quand on est endetté.

A l'aide de documents inconnus du Public Record Office à Londres, M. C. Wyffels, conservateur aux A.G.R., est parvenu à nuancer l'image du commerce flamand en Angleterre avant le conflit de 1270-1274 ${ }^{35}$, provoquant l'embargo total sur l'exportation des laines anglaises vers la Flandre, si bien décrit par H. Berben en 1937 dans les Etudes Pirenne. En 1275, une commission anglo-flamande a établi l'inventaire des pertes respectives: les Anglais auraient perdu $10.627 \mathrm{lb}$. sterl. en Fiandre, les Flamands $5.871 \mathrm{lb}$. en Angleterre. Les chiffres étaient connus. Mais $M$. Wyffels démontre qu'il est nécessaire d'étudier la composition de ce total et de reviser les conclusions qui en sont tirées. En effet dans la perte de $5.871 \mathrm{lb}$. subie par les Flamands sont compris une vieille dette du roi d'Angleterre à certains Gantois de $486 \mathrm{lb}$., $500 \mathrm{lb}$. pour les confiscations d'entre 1270 et 1274 et $2.000 \mathrm{lb}$. d'arrhes payées par les Flamands à des abbayes d'Angleterre pour les récoltes prochaines. En 1270 la valeur véritable des marchandises confisquées n'atteint que $2.700 \mathrm{lb}$. Il est cependant possible que bon nombre de commerçants flamands, alertés par la comtesse de son intention de confisquer les biens anglais, aient par peur de représailles, pris leurs précautions et mis leurs biens en sécurité. Le montant de $2.000 \mathrm{lb}$. du crédit de vente bloqué en 1270 , est cependant un chiffre assez bas pour cette période, ce qui permet de confirmer l'opinion de feu Blockmans selon laquelle avant la guerre économique de 1270-1274, le commerce actif flamand vers l'Angleterre avait sensiblement diminué. Parmi les villes flamandes, Douai, avec $2.429 \mathrm{lb}$. sur $5.770 \mathrm{lb}$., prend la première place dans les relations économiques anglo-flamandes. Suivent de loin : Bruges, Ypres et Gand (ce dernier avec seulement 219 lb.). L'absence totale de Lille dans la liste des pertes (tableau à la page 210 ) est quand même fort étonnante.

Sur l'artisanat bruxellois du métal, signalons deux articles ${ }^{36}$ d'un jeune historien, J.-P. Sosson, qui tendent à prouver que les corporations, l'industrie textile et les lignages n'étaient pas les seuls éléments importants de la vie économique et sociale de Bruxelles aux $\operatorname{Xrv}^{\ominus}$ et $\mathrm{Xv}^{\mathrm{e}}$ siècles. A vrai dire, la tâche est dure pour l'auteur car la documentation est fragmentaire et il est très difficile d'emporter la conviction sans preuve solide. L'originalité de la recherche réside à la fois dans le choix des critères qui permettent de déceler l'importance d'un homme ou d'un groupe (capital de base constitué par l'outillage et le fonds de roulement, biens immeubles, inscription dans la gilde des drapiers) et dans celui des facteurs qui concrétisent la puissance économique de certains artisans établis semble-t-il en marge du monde corporatif et réussissant à s'approcher sinon à entrer dans les lignages. Mais, répétons-le, cette construction ingénieuse reste floue.

35. C. WYFFELS, De Vlaamse handel op Engeland voor het Engels-Vlaams konflikt van 1270-1274. Bijdragen voor de Geschiedenis der Nederlanden, XVII, 1963, pp. 205-213.

36. J.-P. Sosson, Quelques aspects sociaux de l'artisanat bruxellois du métal (1360-1500). Cahiers Bruxellois, t. 6, 1961, pp. 98-122. J.-P. Sosson, L'artisanat Bruxellois du métal. Hiérarchie sociale, salaires et puissance économique (1360-1500), ibidem, t. 7, 1962, pp. 225-258. 
$M^{\text {me }}$ Meynart ${ }^{37}$ de son côté, relate le conflit qui opposa en 1465 le sous drossart de Brabant et la ville de Bruxelles au sujet de l'arrestation et de la condamnation de bourgeois bruxellois en insistant sur l'aspect essentiel de cette action : la défense des privilèges des bourgeois. C'est cette classe sociale, mais dans une autre ville qu'étudient $\mathrm{M}^{\mathrm{me}}$ Chabot et $\mathrm{M}$. Hélin ${ }^{38}$. Sous le titre "Comment devenait-on bourgeois de la cité de Liège ? ", ils nous donnent manifestement ce qui est ou devrait être une partie de l'introduction de leur livre : Les admissions à la bourgeoisie de la cité de Liège (1273-1794) dont nous n'avons pas encore pris connaissance.

Il s'agit d'une énumération chronologique de textes qui fixent les conditions de l'admission. Accessoirement, il est traité des conflits entre les pouvoirs. Un regret : aucun conclusion sur l'évolution de la procédure n'apparaît dans ces quelques pages et c'est grand dommage car le sujet le méritait.

\section{Les nobles et ceux qui s'en approchent}

Après son livre sur la noblesse au Namurois, et ses multiples articles sur ce sujet, $M$. Génicot présente actuellement une petite étude de synthèse, destinée à résumer ses idées sur le problème si actuel de la noblesse médiévale ${ }^{39}$. Il conclut qu'il n'y a pas eu de véritable rupture, mais une adaptation continuelle de la noblesse du haut au bas moyen âge. Au haut moyen âge il n'y a pas de doute que la noblesse ait été une classe sociale, bien distincte des autres classes, et même une classe à statut juridique, se perpétuant par la naissance, peut-être allant de pair avec la détention d'un alleu, jouissant de l'immunité de la personne et des biens et de la direction d'une armée. Au bas moyen âge ce monde noble se ramifie en même temps qu'il s'affaiblit économiquement. La transmission par le sang continue, mais surtout par l'ascendance paternelle. La notion de «liberté subsiste mais dans un sens moins large et plus concret » en échappant aux redevances, et en se plaçant en dehors des institutions judiciaires et politiques ordinaires de l'état. Désormais on rencontre des nobles sans alleu, sans ban, ni justice.

Dans son édition du Viel Rentier (1950), Léo Verriest avait traité du problème de la généalogie de la famille de Pamele-Audenarde. En mettant en œuvre des documents non édités ou moins connus, M. L. Milis, assistant à l'Université de Gand, est arrivé à une meilleure chronologie des seigneurs de Pamele-Audenarde ${ }^{40}$. Il est difficile de résumer ici ses arguments qui sont fort solides. Notons simplement qu'un Thierry $I^{\text {er }}$ (v. 1084- $\left.+1095 / 96\right)$ doit être placé entre Arnoul $I^{\text {r }}$ et Arnoul II. Le Hugues, qu'on retrouve entre 1038 et 1064 doit être

37. A. SMOLAR-Meynart, Un conflit entre la ville de Bruxelles et la justice ducale : l'affaire Van Vytven (1465), ibidem, t. 8, 1963, pp. 1-12.

38. J. Rouhart-Chabot et E. Hetr., Comment devenait-on bourgeois de la cité de liège? Une procédure et ses applications. Bull. Inst. arch. liégeois, t. 76, 1963, pp. 91-114.

39. I. GínICor, La noblesse au Moyen Age dans l'ancienne «France» : continuité, rupture ou évolution. Comparative studirs in Society and History, V, 1962, np. 52-59.

40. L. Milrs, Les scigneurs de Pamele-Audenarde. Vers une meilleure chronologie. Cahiers de Civilisation Médiévale, Université de Poitiers, VI, 1963, pp. 49-53. 
considéré comme le père d'Arnoul $\mathrm{I}^{\text {er }}$ et Thierry I ${ }^{\text {er }}$. Entre Arnoul III (1145/50-1162) et Gislebert $(1166-+1182)$ il faut intercaler Thierry II, dont on a conservé des traces vers 1162-1166. Un tableau synoptique (p. 52) donne une idée claire des filiations. En annexe des extraits de textes sur lesquels repose l'exposé.

Depuis quelque douze ans l'étude de la noblesse au moyen âge dans les Pays-Bas, longtemps restée dans l'ombre, a connu un succès particulier. Les travaux de $M$. Génicot pour le Namurois, de MM. Bonenfant et Despy pour le Brabant, de $M$. Feuchère pour la Flandre, et les études de portée générale de MM. Génicot et Verriest, ont bouleversé nos idées sur le problème. $M$. Despy, professeur à l'Université de Bruxelles, vient de donner un aperçu des résultats acquis, des hypothèses et des théories émises, entre 1952 et $1963^{41}$. Il constate que partout, dans le Namurois, la Flandre, le Brabant, et le pays de Liège, au cours d'une première époque (les temps mérovingiens et carolingiens) la noblesse est une classe "ouverte à ceux qui détiennent des immunités personnelles, ainsi que des pouvoirs de commandement et de juridiction ». Aux $\mathrm{XI}^{\circ}$ et $\mathrm{XII}^{\mathrm{e}}$ siècles, les nobiles continuent à exercer les droits seigneuriaux (surtout de justice). Une charnière se situe entre 1200-1250 : les nobles essaient alors de limiter leur caste à ceux qui sont nés de deux parents nobles. Tout cela les a inévitablement menés à la décadence des $\mathrm{XIII}^{\ominus}$, $\mathrm{XIV}^{\circ}$ et $\mathbf{X V}^{\circ}$ siècles. $\mathrm{M}$. Despy se dresse avec violence contre les théories que Léo Verriest - le doyen des historiens belges, mort il y a quelques semaines - a développées dans son livre sur la noblesse, en 1959.

En partant d'une source narrative qui lui est particulièrement bien connue, les Annales Cameracenses de Lambert de Wattrelos (écrivant entre 1152 et 1170), M. F. Vercauteren ${ }^{42}$ essaye en s'aidant de chartes cambrésiennes flamandes et hennuyères, d'établir d'une façon qu'il se défend de croire définitive la généalogie de la famille du chroniqueur dont la fortune et la situation semblent n'avoir été que modestement importantes aux $\mathrm{XI}^{\mathrm{e}}$ et $\mathrm{XII}^{\mathrm{e}}$ siècles.

Une étude généalogique sur la famille «van Bellegem 》 dont plusieurs membres ont porté au XIII ${ }^{\circ}$ siècle le titre de panetier héréditaire et de "dispensator 》 du comte de Flandre a été l'occasion pour E. Warlop, archiviste-paléographe aux Archives de l'Etat à Bruges, élève du professeur Strubbe, d'attirer l'attention sur la fonction de «dispensator » à la cour comtale flamande ${ }^{43}$. Il s'agit d'une des charges auliques mineures, dont le titre est devenu héréditaire au $\mathrm{XIII}^{\circ}$ siècle et $\mathrm{d}^{\prime}$ abord dans la famille "van Bellegem ». En ce qui concerne les fonctions de * dispensator 》, les conclusions de l'auteur restent malheureusement assez vagues. On regrette notamment que l'auteur n'ait pas rapproché le * dispensator » des sénéchaux locaux du XII siècle.

En relatant le conflit qui oppose, de 1343 à 1355, le veneur de

41. G. Despy, Sur la noblesse dans les principautés belges au Moyen Age. R.B.P.F., XII, 1963, pp. 471-486.

42. F. Vercautreren, Une parentèle dans la France $d u$ Nord aux $X I^{\circ}$ et $X I I^{\circ}$ siècles. Le Moyen Age, t. 69, 1963, pp. 223-245.

43. E. WARLOP, De dispensator van de graaf van Vlaanderen (1093-einde $13^{\circ}$ eeurw). Versl. en Med. van De Leiegouw, V, 1963, pp. 31-45. 
Hainaut au receveur du comté, $\mathbf{M}^{\text {11e }}$ Bruwier ${ }^{44}$ donne un exemple précis de la différence qui existe au XIV $^{\circ}$ siècle entre les conceptions d'un féodal, officier du comte (le veneur) et d'un fonctionnaire défendant les droits du même comte (le receveur). C'est à l'occasion d'une demande de confirmation de son fief faite par le veneur que le receveur intervint pour réclamer des preuves et provoquer une enquête qui aboutit à une ordonnance limitant considérablement les droits abusifs du veneur dont la famille détenait la charge depuis longtemps déjà.

\section{Les églises et les fidèles}

Il est significatif qu'à un moment où l'église catholique, réunie en concile, s'interroge sur elle-même et sur la manière dont une foi chrétienne véritablement vécue pourrait pénétrer plus profondément dans l'âme et l'esprit de la grande masse - à un moment aussi où les recherches de sociologie religieuse ont atteint un certain degré de maturité et ont fait la preuve, sinon de leur utilité du moins de leur caractère scientifique - qu'à un tel moment, paraisse, dans une collection qui s'adresse au grand public et au cercle restreint des historiens et théologiens professionnels, un livre important, sur le sentiment religieux en Flandre à la fin du moyen âge ${ }^{45}$, thèse d'Université de l'abbé Toussaert. Il rompt totalement avec le point de vue traditionnel qui consiste à aborder le sujet à travers l'histoire de la spiritualité, ce qui mène ainsi à des conclusions que l'auteur juge beaucoup trop optimistes. Pour mesurer le sentiment religieux non pas d'une élite, mais de la masse, il s'est attaché avant tout à l'étude de la pratique religieuse, sous ses divers aspects, en faisant appel aux sources et méthodes statistiques aussi souvent que possible. Il résulte de son enquête que, malgré le succès des processions, du culte de la Vierge et des saints, des fêtes liturgiques et autres manifestations de masse qui, en somme, ne sont que le côté extérieur de la religion, où les frontières entre la vraie religiosité et l'extériorisation profane, voire la superstition sont à peine discernables, la pratique religieuse aux $\mathbf{X I V}^{\circ}-\mathbf{X V}^{\circ}$ siècles en Flandre maritime - car tel est en fait le cadre géographique - a été beaucoup plus faible que l'on ne se plaît généralement à le croire. Le devoir pascal, par exemple est très irrégulièrement observé, principalement dans les villes (notamment dans l'église Saint-Jacques à Bruges) mais la situation s'améliore dans les villages plus petits. L'assistance régulière à la messe dominicale, n'est le fait que d'une minorité de paroissiens. Les «indices indirects", comme les nomme l'abbé Toussaert, les traces de vie religieuse dans la vie de tous les jours qui deviennent visibles par exemple dans l'attitude des masses vis-à-vis du mariage confirment et complètent ce tableau assez sombre, où les paradoxes toutefois ne manquent pas. Paradoxe, en effet, que la consternation générale provoquée par l'interdit et l'indifférence que reflète le nombre

44. M. BRUWIER, Un conflit d'administration au XIV siècle : les droits du veneur de Hainaut. Le Moyen Age, t. 69, 1963, pp. 541-553.

45. J. Toussaert, Le sentiment religieux en Flandre à la fin du Moyen Age. Préface de Michel Mollat. Paris, Librairie Plon, Coll. « Civilisations d'hier et d'aujourd'hui $\$$ 1963, 886 pages + résumés en néerlandais et en allemand. 
incroyablement grand d'excommuniés. Paradoxales aussi les très nombreuses vocations. Paradoxe, enfin, cette observance générale du carême et de l'abstinence.

Il va de soi qu'en présence de tels résultats, déroutants parfois, et souvent contradictoires, leur interprétation n'était pas pour l'auteur tâche facile. Aussi son explication est-elle très complexe. Relevons-en néanmoins brièvement les éléments principaux : la misère matérielle et morale des masses pendant ces deux siècles d'épidémies, de famines et de guerres; les troubles politiques, auxquels s'ajoutent Ie Grand Schisme et les préoccupations temporelles des évêques sèment le doute dans les esprits; le caractère rudimentaire et superficiel de l'instruction religieuse des masses qui, malgré la bonne volonté du bas clergé ne repose généralement que sur les parents et la famille.

Dans le cadre de cette chronique nous n'avons pu résumer que d'une manière très imparfaite les principales conclusions du livre bouleversant de l'abbé Toussaert. Nous sommes conscients de l'injustice que nous commettons ainsi à son égard. Il aurait sans doute préféré que nous fassions ressortir davantage les nuances, les doutes et les réserves qu'il a mis dans son exposé. Nous le comprenons, car nombreux seront ceux qui l'attaqueront. Les uns parce qu'ils n'aiment pas l'optique sociologique dans laquelle il a situé son enquête et dont l'importance pour l'étude des mentalités collectives - l'une des plus difficiles qui soit d'ailleurs - leur échappe encore. Les autres parce qu'ils essaieront de ruiner les conclusions du livre en le décomposant jusque dans ses moindres détails. Il faut avouer que de ce point de vue, hélas, le livre prête aisément le flanc à la critique, même pour ceux qui admirent ce qui en fait sa nouveauté, son originalité et son importance, à savoir la façon dont l'auteur pose les problèmes, les seuls vrais problèmes en histoire, ceux du groupe. En effet, beaucoup de détails dans ce beau livre laissent à désirer. La présentation d'abord. Les références ne sont pas toujours exactes, ni même compréhensibles. Elles sont d'ailleurs reléguées à la fin du livre, ce qui est incommode. La plupart des citations bibliographiques contiennent chacune au moins une faute et malgré l'abondance de la bibliographie il y a beaucoup de lacunes (par exemple dans la bibliographie sur Tanchelin). Sur beaucoup de questions de détail des interprétations erronées peuvent être signalées (cf. les remarques dénuées de toute sérénité de $\mathrm{A}$. Viaene, dans Biekorf, $64^{\circ}$ année, 1963, pp. 145-150, 183-189, 275-280). On ressent parfois des doutes lorsque l'auteur, à l'aide de quelques indices transforme des "impressions » en hypothèses. Cet « impressionnisme », dû souvent, il faut l'avouer, à l'état des sources, nous inquiète, surtout lorsqu'un style, très spontané à vrai dire, mais trop facile lui vient en aide.

Arrêtons-nous là, cependant, et laissons aux inévitables détracteurs du livre de l'abbé Toussaert le soin d'allonger cette liste de critiques. Terminons par ce mot de la préface de M. Michel Mollat : " le lecteur qui ne serait pas convaincu ne demeurera pas indifférent ». Il s'agit en effet d'un livre peut-être imparfait, mais en tout cas très important, dans un domaine de l'histoire qui, pour reprendre une autre expression de $M$. Mollat, est peut-être un des plus délicats, mais, qui sait, aussi le plus décisif. 
M. Milis, assistant à Gand, s'est spécialisé dans l'histoire de l'abbaye d'Eename. Il a étudié, en 1961, l'histoire de l'institution, et prépare une édition des actes ou des analyses d'actes de l'abbaye antérieurs à 1200 . Cette année nous lui devons un article sur la bibliothèque de l'institution ${ }^{46}$. Après avoir donné le texte de deux anciens catalogues, datés respectivement de 1549 et 1574, l'auteur note que ces listes (d'une trentaine d'œuvres) ne sont pas complètes, et qu'elles ne donnent probablement qu'un choix des manuscrits les plus importants (c'est le cas de la liste de 1574) ou un aperçu des livres du réfectoire (c'est le cas de 1549). Le trésor n'était pas abondant, mais sa valeur était grande. Peu après 1574 à la suite d'importantes difficultés, la bibliothèque a été dispersée en grande partie, telle cette fameuse Chronica Eusebii et Sigeberti, vendue à l'humaniste Juste Lipse, et conservée aujourd'hui à la bibliothèque de l'Université de Leyde. D'autres manuscrits sont parvenus à Oxford à la Bibliothèque de l'Université et aux Archives de l'Etat à Gand, ainsi qu'à la bibliothèque Royale à Bruxelles. A l'occasion de la suppression de l'abbaye en 1796, ce qui restait de la bibliothèque a été confisqué, et transmis à la bibliothèque départementale, puis à celle de la ville de Gand, pour finalement être classé à la bibliothèque de l'Université de Gand. Il est encore impossible de dresser pour l'instant une liste complète des livres provenant de l'abbaye d'Eename.

L'ordre religieux et militaire de Saint-Jean de Jérusalem comptait six commanderies en Belgique au $\mathrm{XVIII}^{\ominus}$ siecle. Celle de Villers-leTemple près de Huy vient de trouver son historien ${ }^{47}$. Le lecteur reste malheureusement sur sa faim car rien d'essentiel n'est dit. Tout est anecdote et récit de seconde main.

Quant à l'étude de $\mathrm{J}$. De Cuyper consacrée à la chapelle comtale de Courtrai, à sa construction de 1370 à 1374 et à sa reconstruction après la destruction de $1382^{48}$, bien qu'elle soit surtout une contribution à l'histoire de l'art, est signalée ici à cause des documents inédits dont elle fait usage et des données qu'elle fournit sur les relations entre le comte Louis de Maele et la ville de Courtrai.

La tradition d'un séjour légendaire de sainte Walburge à Anvers repose sur l'imagination d'un hagiographe anglais $\mathrm{du} \mathrm{Xv}^{\circ}$ siècle, Jean Pole ou de la Pole, dont l'œuvre était considérée comme perdue. Le père Coens, président des Bollandistes, en a toutefois retrouvé un fragment dans le codex 680 de la bibliothèque des Bollandistes à Bruxelles. Ce codex est un bréviaire des environs de l'année 1471, provenant de la collégiale Ste-Walburge à Zutphen (Pays-Bas) qui contient des données hagiographiques assez précises sur des saints particulièrement vénérés à Zutphen et notamment sainte Walburge. Le savant bollandiste publie les textes de ce codex qui concerne la sainte anglaise ${ }^{49}$.

46. L. MILIs, De kloosterbibliotheek van Ename. Handelingen van de Geschied- en Oudheidkundige Kring van Oudenaarde, XV, 1963.

47. F. L. Verbiest, La commanderie de Villers-Le-Temple, Bull. Inst. Arch. Liégeois, t. 75,1962 , pp. $37-100$.

48. J. DE CUYPER, De gravenkapel van Kortrijk. Opbouw (circa 1370-1374) en herstel na de ramp van 1382. Versl. en Med. van De Leiegouw, IV, 1962, pp. 5-54.

49. M. Conns, s. j., Le séjour légendaire de sainte Walburge à Anvers. Analecta Bollandiana, LXXX, 1962, pp. 345-360. 
Les nombreuses publications de $M$. A. D'Haenens, conservateur du département des archives et manuscrits de la bibliothèque de 1'Université de Louvain, ont fait connaître la très riche collection de comptes de l'abbaye Saint-Martin de Tournai de la première moitié du $\mathrm{XIV}^{\ominus}$ siècle et leur importance pour l'histoire de cette institution. Cela ne signifie toutefois point que la publication de ces comptes soit devenue inutile, au contraire. Ils fournissent en effet une documentation abondante pour l'histoire économique du XIV siècle, que l'auteur, dans ses nombreuses études, n'a pas eu l'occasion d'utiliser de manière exhaustive. C'est pourquoi l'on saura gré à $M$. D'Haenens d'avoir entrepris la lourde tâche de leur publication in extenso et de l'avoir menée à bonne fin ${ }^{50}$. L'introduction de 115 pages se limite évidemment à la critique externe et interne des documents, leur interprétation étant laissée aux nombreux chercheurs qui les utiliseront et particulièrement aux spécialistes de l'histoire des prix et des monnaies, de l'agriculture et de la fiscalité papale et royale. Cette utilisation se trouve facilitée par un registre des noms de lieux et de personnes et par un index rerum, qui constitue en même temps un glossaire.

L'étude critique ${ }^{51}$ que le père $N$. Huyghebaert vient de consacrer à la charte de fondation de l'abbaye de Phalempin de 1039, est une contribution importante à la diplomatique des chartes des évêques de Noyon-Tournai dont l'auteur prépare l'édition. En établissant cette fois l'authenticité de la charte, qu'il avait rejetée dans une étude antérieure, l'auteur est obligé, en effet, de prendre en considération la mention "Hugo Tornacensis ecclesiæ cancellarius » et d'accepter, en se corrigeant, l'existence de deux chanceliers dans l'évêché, l'un à Noyon et l'autre à Tournai. L'existence d'un chancelier à Tournai témoigne de l'affaiblissement du pouvoir des rois capétiens vers la fin du règne de Robert le Pieux et de l'indépendance de la politique ecclésiastique des comtes de Flandre Baudouin IV et V. De ce point de vue l'article du père Huyghebaert est une contribution richement documentée à l'histoire ecclésiastique de la Flandre vers le milieu du $\mathrm{XI}^{\circ}$ siècle.

Par ailleurs, c'est en se livrant à des exercices de chronologie, pour lesquels il a une réelle prédilection que le professeur P. Bonenfant date de 1165-67 une charte de Nicolas $\mathrm{I}^{\text {er }}$ de Cambrai, qui attribue à l'abbé de Jette une cure revendiquée par un certain Jonas qui ne l'obtint point parce que condamné plusieurs fois pour catharisme ${ }^{52}$. En identifiant les quatre prélats qui ont condamné Jonas avec les archevêques de Cologne et de Trèves et avec deux évêques de Liège, l'auteur prouve incontestablement que Jonas fut itinérant et peut-être même propagandiste. Nous ne le suivons toutefois pas quand il se sert des dates des règnes des évêques de Liège (1145-1167) pour rejeter la thèse défendue

50. A. D'Haengns, Comptes et documents de l'abbaye de Saint-Martin de Tournai sous l'administration des gardiens royaux (1312-1355). Bruxelles, Comm. Royale d'Histoire, série in-8 1962,883 p.

51. N. Huyghebaert, Hugo Tornacensis ecclesie cancellarius, Examen critique de la charte de fondation de l'abbaye de Phalempin (1039). Bull. Comm. Royale d'Histoire, CXXVIII, 1962, pp. 183-273.

52. P. Botenfant, Un clerc cathate en Lotharingie au milieu du XII siècle. Le Moyen Age, t. 69,1963, pp. 271-279. 
par J. Russell selon laquelle il $\mathrm{y}$ avait des Cathares à Liège au $\mathrm{XI}^{\mathrm{O}}$ siècle ${ }^{53}$.

Les trésors contenus dans les archives privées ont déjà souvent provoqué la surprise des historiens. Tel ce fragment d'un cartulaire du début du XIII ${ }^{\mathrm{e}}$ siècle du chapitre d'Harelbeke reposant tranquillement (depuis quand ?) dans les archives de la famille de Plotho d'Ingelmunster, récemment acquis par les Archives de l'Etat de Bruges, telle aussi la collection du marquis de Beauffort à Bruxelles, qui contient les registres si précieux de J. R. Hannedouche de Rebecque, où figurent des transcriptions faites par ce généalogiste en 1657. L'importance de ces documents découle du fait qu'ils concernent des institutions de la région d'Aire-sur-la-Lys (Pas-de-Calais), dont les archives ont assez largement ou presque entièrement disparu, notamment celles des abbayes de Blandecques et de Ham et celles du chapitre d'Aire. Les registres d'Hannedouche de Rebecques n'étaient pas inconnues : le professeur Vercauteren les avait mis en ceuvre pour ses Actes des Comtes de Flandre en 1938 et A. Verhulst et W. Prevenier les ont dépouillés en vue de leur prochaine édition de la suite du livre de $\mathbf{M}$. Vercauteren. M. E. Brouette les a aussi consultés pour un court article, contenant les regestes des actes des comtes de Flandre, inconnus et non édités, qui se trouvent dans ces registres ${ }^{54}$. Ce travail nous a profondément déçu à cause du manque total de soin apporté dans les identifications et de l'absence de la moindre critique historique qu'on a le droit et le devoir d'exiger d'un travail de ce genre. Les analyses sont souvent un amalgame d'inexactitudes dans les détails et d'une méthode périmée. En laissant de côté toutes les traditions de texte autres que celles trouvées dans son cher manuscrit de Rebecque, qu'il cite - horresco referens - en outre uniquement d'après une copie du $\mathrm{Xx}^{\ominus}$ siècle faite par $\mathrm{R}$. Rodière et déposé aux $\mathrm{A}$. D. d'Arras, $M$. Brouette reste prisonnier des pires traditions de la Handschriftenausgabe des amateurs les moins avisés du XIX ${ }^{\mathrm{e}}$ siècle. Des remarques concrètes seront formulées ailleurs ${ }^{55}$. Ce qu'on a voulu accuser ici une fois de plus, c'est la méthode qui consiste à présenter aux érudits, comme un travail accompli et critique, des fiches plus ou moins bien classées.

\section{La politique intérieure et les relations internationales}

En 1040, l'empereur Henri III cède à l'évêque de Liège le comté de Haspinga dont on ignore la situation exacte, la consistance et les limites. En identifiant le comté de Haspinga à l'avouerie de Hesbaye et en se servant de mentions assez tardives des fiefs et des biens de cette dernière, M. Baerten ${ }^{56}$ situe le comté entre Meuse, Geer et Mehaigne à l'Ouest de Liège. Des textes de 956 et 961 confirment cette extension et des diplômes de 898 et 919 lui permettent d'englober Maestricht

53. Ici même, t. 45,1963 , p. 78 .

54. E. BRovette, Documents inédits des comtes et comtesses de Flandre relatífs à des monastères de l'Artois. Archives, Bibliothèques et Musées de Belgique, XXXIII, 1962, pp. $212-220$.

55. Bijdragen voor de Geschiedenis der Nederlanden, t. XVIII, à paraître prochainement.

56. J. BAERTEN, Le comté de Haspinga et l'avouerie de Hesbaye (IX'-XII' siècles). Rev. Belge Ph. et Hist., t. 40, 1962, pp. 1149-1167. 
dans le comté qui existait - semble-t-il — à la fin du $\mathrm{Ix}^{\ominus}$ siècle déjà. Cette première partie de l'article est très convaincante. La seconde, qui essaie de démontrer que l'évêque a confié à un avoué son nouveau bien l'est beaucoup moins. Car malgré la coïncidence entre les deux domaines, il s'écoule un siècle entre l'acquisition du comté et l'apparition du titre d'avoué. Et les comparaisons avec d'autres régions absorbées par la Meuse sont trop superficielles pour emporter notre assentiment. Mais peut-être est-il impossible de le faire en l'absence de textes probants ?

En répondant par la négative à la question : A-t-il existé un acte d'inféodation du comté de Looz à l'église liégeoise ? le même historien ${ }^{57}$ nous donne une autre contribution à la vie intérieure de la principauté de Liège. Il discute les thèses et les hypothèses de nombreux historiens liégeois et lossains en remontant toujours jusqu'à leurs sources. Parmi celles-ci, la chronique de Hocsem du XIV siècle et un inventaire des chartes de la cathédrale de 1290 retiennent plus particulièrement son attention. Elles lui permettent de dire avec vraisemblance que l'inféodation s'est faite au $\mathrm{xI}^{\mathrm{c}}$, au moment où, en 1040 , le comté de Haspinga est cédé à l'évêque Nithard, mais après que le comté de Looz fut devenu fief du comté d'Haspinga à la suite d'un accord réalisé entre les comtes de Looz et de Haspinga.

La paix de Fexhe de 1316 a toujours été considérée comme un compromis des intérêts politiques du prince, du chapitre cathédral, des grands laïcs et des forces urbaines. $M$. J. Lejeune ${ }^{58}$ repose le problème des influences et cherche à déceler, sinon à mesurer, l'importance des conceptions politiques de certains clercs liégeois fréquentant les cours de Paris où la philosophie sociale et politique d'Aristote est enseignée depuis le milieu du XIII ${ }^{\mathrm{e}}$ siècle. Parmi ces Liégeois, le chanoine Godefroid de Fontaines, originaire de la Hesbaye, et professeur à Paris, où il a d'ailleurs reçu sa formation, est un cas bien intéressant. De la comparaison de plusieurs de ses écrits - notamment des quodlibet - et de quelques paragraphes de la Paix de Fexhe il ressort que l'influence des premiers sur les seconds est indéniable. Ce n'est pas un mince mérite que de nous l'avoir conté.

On sait combien il est difficile de donner une date à des keuren sans dates, sans formules de protocole ou d'eschatocole permettant d'en identifier l'auteur et de fixer le moment précis de leur rédaction. M. E. Warlop, s'est attaqué au célèbre privilège pour le Franc de Bruges (= châtellenie ayant Bruges comme centre), que Vredius avait considéré comme un texte provisoire rédigé en $1190^{59}$ et il a résolu l'énigme avec perspicacité. Il a remarqué que le texte contient deux clauses finales, exactement comme c'est le cas dans le privilège pour la Zélande. Comme en Zélande, le texte du Franc est donc composé de deux parties nettement distinctes. Le terminus ante quem de la deuxième partie est 1224, puisqu'on fait mention du châtelain, qui disparaît en

57. Archives, Bibliothèques et Musées de Belgique, t. 33, 1962, pp. 221-234.

58. J. Lejeune, De Godefroid de Fontaines à la Paix de Fexhe (1316). Annuaire de la commission communale de l'histoire de l'ancien pays de Liège, t. 6, 1962, pp. 1215-1261.

59. E. WARLOP, De Keurbrief van het Brugse Vrije. Handelingen Société d'Emulation te Brugge, XCIX, 1962, pp. 161-186. 
1224 par suite de la vente de châtellenie à Jeanne de Constantinople. Ensuite M. W. analyse en détail le style, les structures, le choix d'expressions et aussi les dispositions de la pièce, pour arriver à la conviction qu'elle peut être décomposée en effet en deux parties et que la première se termine par le $\$ 21$. Cette première partie, qu'on a appelée plus tard la cura comitis Philippi, est née vers 1190 et a tout à fait l'aspect d'un projet, qu'on avait l'intention de compléter plus tard. La deuxième partie date donc d'avant octobre 1224 : elle fut composée en plusieurs étapes entre 1190 et 1224, les derniers paragraphes ( $\$ 62$ et 64 ) à la fin de 1223 ou début de 1224 . La comtesse Jeanne a probablement ratifié vers 1224 l'ensemble de la cura de Philippe d'Alsace avec les additions ajoutées à ce texte jusqu'à ce moment.

$L$ 'argumentation que $M$. W. nous propose pour défendre sa thèse, est convaincante.

Le comte Baudouin IX de Flandre (VI en Hainaut), devenu empereur de Constantinople en 1204, a joué un rôle important dans la politique internationale de son temps. Une nouvelle biographie due à $M$. W. Prevenier, chef de travaux à l'Université de Gand, paraîtra prochainement dans le Nationaal Biografisch Woordenboek que vient d'entamer la Koninklijke Vlaamse Academië van België. Mais ce n'est pas seulement sur le continent que l'on s'intéresse à ce comte : un érudit américain, J. C. Moore a traité des relations de Baudouin IX et du roi de France avec le pape ${ }^{60}$. Cette étude veut démontrer que le comte de Flandre tout autant que le roi de France ont réussi à faire intervenir l'autorité ecclésiastique et particulièrement le pape, dans la lutte qui les oppose. En juin 1196, Baudouin IX a encore juré fidélité et fait hommage à Compiègne comme vassal du roi de France. Mais en 1197 un conflit éclate qui déclenche une guerre implacable entre suzerain et vassal jusqu'en janvier 1200 et qui pousse le comte de Flandre vers une alliance avec l'Angleterre. Puisqu'en 1196 Baudouin avait juré fidélité sous peine d'excommunication en cas de rupture, Philippe Auguste incite les évêques des provinces ecclésiastiques, dont ressortissent la Flandre et le Hainaut, et particulièrement son oncle l'archevêque de Reims (Guillaume de Champagne) à jeter l'interdit sur les pays de son vassal. Baudouin IX a donc intrigué à Rome pour prévenir l'application de l'excommunication imminente. L'accession en 1198 d'un nouveau pape, Innocent III, lui donna l'occasion de préparer un complot ingénieux. Au printemps de 1199 les délégués du comte sont parvenus à faire croire à Innocent III que le serment aurait en réalité été prêté en 1195 à Vernon, et qu'en juin 1196 Philippe Auguste aurait libéré Baudouin de ce serment (et de la sanction); le roi de France aurait présenté le texte de 1195 comme l'accord final, d'où l'interdit. En fait cette histoire des dcux serments n'est qu'une invention de Baudouin pour éviter l'excommunication, ce qui lui a réussi puisque le pape a ordonné à l'archevêque de Reims d'y mettre fin. L'exposé et les arguments de $M$. Moore sont convaincants. Il démontre que ce cas n'est pas le seul dans la controverse flamando-française. Des intri-

60. J. C. Moore, Count Baldwin IX of Flanders, Philip Augustus ant the papal power, Speculum, XXXVII, 1962, pp. 79-89. 
gues à Rome, cette fois par Philippe-Auguste, ont permis au roi de marier Mathilde, la fille de Pierre, comte de Nevers et d'Auxerre, à Hervé de Donzy, et non à Philippe, frère de Baudouin IX, comme il était convenu en 1193, sous peine de censure ecclésiastique.

M. Camille Tihon, archiviste général du Royaume honoraire, a publié le second tome des lettres du pape Grégoire IX, pour la période qui va du 5 janvier 1372 au 4 janvier $1373^{61}$. Les quelque 1600 analyses se réfèrent à des actes des registra Avenionensia et Vaticana, conservés au Vatican. En 1958, M. Tihon avait publié le premier tome d'une série, qui en comprendra trois, et qui est d'une très haute qualité tant par les analyses que par les notes critiques. Espérons que les indices et l'introduction qui sont annoncés pour le tome III ne tarderont pas à paraître, afin de permettre la totale exploitation de cette riche mine de renseignements.

\section{Le Droit}

Il y a dans les rapports entre individus ou entre individus et institutions des moments et des cas où des distinctions s'établissent dans la pratique avant que la doctrine ne soit formée. C'est ce que suggère l'article clair et lumineux du professeur Ganshof ${ }^{62}$, consacré à l'examen d'une notice des années $1100-1132$ où il est fait mention de deux donations, avec réserve d'usufruit, pour l'abbaye d'Eename et d'une usurpation commise par un tiers vraisemblablement après la mort des donateurs. Cette usurpation fut suivie de deux procès. Le premier jugement condamna le coupable à restitution, le second établit que l'abbaye était seule en possession du droit de propriété. Ainsi il s'agit, dans le premier cas d'action possessoire et dans le second d'action pétitoire. Et tout cela sans influence de la doctrine et par devant une cour seigneuriale et non pas en la cour du comte.

Le livre de droit connu sous le nom de «Conseil à un ami » de Pierre de Fontaines est en réalité une recueil de droit coutumier vermandois de la seconde moitié du XIII ${ }^{\ominus}$ siècle. Il en existe une traduction flamande dans un manuscrit $\mathrm{du}_{\mathrm{Xv}} \mathrm{v}^{\circ}$ de la Bibliothèque Royale de Belgique. En quelque vingt pages alertes et vives, le professeur Strubbe ${ }^{63}$ démontre que cette traduction date du début du XIv ${ }^{\theta}$ et qu'elle fut faite par ou pour le bailli de la cour féodale que l'abbaye de Saint-Quentin avait en Frandre dans la région d'Oostkerke où la langue véhiculaire était le flamand mais la pratique judiciaire vermandoise donc d'expression française. Et cela au moins jusqu'au $x v^{\ominus}$ siècle, époque où fut écrite la copie qui a permis à $M$. Strubbe d'écrire son bel article.

A propos d'un incunable de 1477 des « Flores utriusque juris » du chroniqueur liégeois, Jean de Hocsem, incunable qu'il a eu le bonheur d'identifier en 1959 déjà $M$. R. Feenstra ${ }^{64}$ retrace la carrière de

61. C. TiHon, Lettres de Grégoire XI (1371-1378), t. II (n ${ }^{\circ}$ 1390-2976), Textes et analyses, Bruxelles, Rome, 1962, 710 pp. (Analecta Vaticano Belgica).

62. F. Ganshof, Un cas précoce de distinction entre l'action possessoire et l'action pétitoire en Flandre. Le Moyen Age, t. 69, 1963, pp. 259-270.

63. E. I. Strubre, De Nederlandse conseil d̀ un ami von $P$. De Fontaines. Rev. d'hist. du droit, t. 31, pp. 323-345.

64. Les flores utriusque furis de fean de Hocsem et leur édition au XV' siècle. Ibidem, pp. 486-519. 
l'écolâtre de Saint Lambert en insistant sur sa formation juridique, son rôle politique dans la principauté au XIV $^{\dagger}$ et l'originalité du répertoire juridique qui a eu les honneurs de la publication au $\mathbf{x v}^{\circ}$ siècle déjà.

Dans la châtellenie d'Ypres, la seigneurie de Warneton appartint aux de Béthune jusqu'en 1263. Leur bailli Gautier d'Arrouaise ayant commis beaucoup d'abus et surtout d'exactions, une enquête fut ouverte en 1249-1250 et de nombreuses personnes furent interrogées. Soixanteneuf témoignages nous sont parvenus. Ils viennent d'être publiés par les soins dc $\mathrm{M}$. C. Wyffels ${ }^{65}$ qui met ainsi à la disposition des historiens un texte riche et précieux pour la connaissance d'une des institutions les plus importantes du moyen âge et pour l'étude de certaines catégories sociales notamment les cahorsins, les usuriers et les drapiers.

Le $1^{\text {er }}$ janvier 1469, Charles le Téméraire restreint la compétence du sénéchal de Brabant et organise son office sur des bases nouvelles. Le texte de cette ordonnance était connu. Ce qu'on ignorait c'est que le sénéchal en fonction avait protesté par écrit. Madame Meynart a eu le mérite d'identifier cette protestation. Elle publie ${ }^{66}$ les deux textes en les faisant précéder d'une introduction qui compare chaque point de l'un à chaque point de l'autre et explique que le motif principal de la résistance du sénéchal est - on s'en doutait un peu - la diminution de ses profits.

\section{Les économies}

\section{LES TEMPS MODERNES}

Les finances publiques des Pays-Bas du $\mathrm{XvI}^{\mathrm{c}}$ siècle n'ont pas encore fait l'objet d'une étude systématique. Des articles récents, comme celui de F. Braudel sur les emprunts de Charles-Quint, montrent cependant l'intérêt croissant qu'on porte à cette question. L'étude de $M$. Baelde, jeune spécialiste de l'histoire des institutions centrales du $\mathrm{XVI}^{\circ}$ siècle, ne veut être qu'une première esquisse de la politique financière et de l'évolution du domaine princier à l'époque de CharlesQuint et au début du règne de Philippe II ${ }^{67}$. L'auteur y suit pas à pas le déficit croissant des finances sous Charles-Quint. L'effondrement spectaculaire des revenus du domaine après 1552 , illustré à l'aide de chiffres, en fut une des conséquences les plus apparentes.

M. J. Craeybeckx est revenu récemment sur la signification du fameux dixième denier du duc d'Albe dans le déroulement de la révolte des Pays-Bas, question qu'il avait déjà partiellement abordée dans un article paru ici-même en 1947. En élargissant sa base d'investigation, l'auteur a pu établir que le dixième denier $(10 \%$ de la valeur des marchandises vendues ou exportées), impôt très élevé en effet, n'a nullement causé la crise économique qui sévissait d'ailleurs depuis plusieurs années d'une part et que, d'autre part, l'opinion était tellement

65. C. WyFFELS, Getuigenverhoor betreffende de ambtsmisbruiken van de baljuw van de heerlijkheid Waasten (27 feb. 1250). Bull. Com. Roy anc. lois et ordon. de Belgique, t. 20, $1961-62$, pp. 319-359.

66. A. MEYNART, L'instruction de 1469 pour le Sénéchal de Brabant et son application. Ibidem, pp. $361-402$.

67. M. BAELDE, Financiële politiek en domaniale evolutie on de Nederlanden onder Karel $V$ en Filips II. Tijdschrift voor Geschiedenis, 76, Groningue, 1963, pp. 14-33. 
montée contre cette taxe qu'elle n'a même pas été perçue. La tentative avortée d'instaurer un impôt perpétuel, impliquant la mise en sommeil des assemblées d'états, a freiné pour les siècles à venir le triomphe de l'absolutisme aux Pays-Bas ${ }^{68}$.

L'histoire économique d'Anvers a fait l'objet, ces dernières années, de plusieurs contributions importantes. Elle vient d'être étudiée à nouveau dans un ouvrage qui est sans conteste le plus remarquable de ceux consacrés à ce sujet : $\mathrm{H}$. van der Wee : The growth of the Antwerp Market and the european economy (fourteenth-sixteenth centuries) ${ }^{69}$.

L'auteur, qui unit les qualités de l'économiste à celles de l'historien, a étudié le développement du marché anversois dans un cadre très large, aussi bien au point de vue chronologique (de la première moitié du XIV" siècle à 1600) que du point de vue géographique (il étudie en fait l'histoire économique de tout le duché de Brabant); il traite de tous les aspects de la vie économique - la démographie, l'agriculture, l'industrie, le commerce - et allie la connaissance approfondie des sources et d'une abondante littérature à une rare originalité de vues. L'ouvrage étant sorti de presse tout récemment, nous devons nous borner ici à signaler ces mérites évidents à première vue.

D'autre part le discours commémoratif que le professeur J. A. Van Houtte $^{70}$ a fait le 8 décembre 1962 , à l'occasion du $450^{\circ}$ anniversaire de Gérard Mercator, n'est pas sans rapport avec la métropole. Il résume assez bien les récentes publications sur le grand humaniste flamand et se fonde principalement sur une série de contributions et de documents réunis dans le numéro spécial des « Duisburger Forschungen » (1962).

L'histoire économique et sociale des campagnes flamandes continue à préoccuper les chercheurs. Deux contributions concernent cette année la propriété et les exploitations rurales. Dans les deux cas, les auteurs ont surtout puisé dans les cahiers du $\mathrm{XX}^{\mathrm{c}}$ denier dont l'importance a été soulignée maintes fois.

Le premier article ${ }^{71}$ est de $M$. De Rammelaere, élève du Prof. Verlinden. Il est très important à différents points de vue et notamment parce qu'il exploite pour la première fois un nouveau type de sources : les ommestellingen, cahiers d'impôts sur les biens immobiliers. Comme ces registres ne donnent pas la superficie totale et exacte des exploitations, il est à prévoir que certains historiens seront réticents, mais comme ce sont les seuls documents que l'on possède en assez grande quantité pour établir une évolution du nombre et de la superficie des exploitations agricoles, il nous semble qu'ils ne sont pas à négliger. Pour la fin du Xvi ${ }^{e}$ siècle, les conclusions de M. De Ramme-

68. J. Crafybeckx, Alva's tiende penning, een mythe? Bijdragen en modedelingen van het Historisch Genootschap, 76, Groningue, 1962, pp. 10-42.

69. 3 vol., Louvain, 1963. I, Statistics. II, Interpretation. III. Graphs.

70. Gerard Mercator. 1512-1594. Herdenkingsrede uitgesproken ter gelegenheid van de $450^{\circ}$ verjaring van Mercators geboorte in de openbare algemene vergadering van de Academie op 8 december 1962. Mededelingen v. d. Kon. VL. Ac. - Klasse der Letteren, jrg. XXV, 1963, nr I.

71. DE Rammelaere C., Bijdrage tot te landbouwgeschiedenis in Zuid Oostelaanderen (15101790) (Contribution à l'histoire agraire dans le sud de la Flandre Orientale 1570-1790). Handelingen der Maatschappij voor Geschiedenis en Oudheidkunde te Gent, nouvelle série, XVI, 1962, pp. 1-40. 
laere se résument comme suit : la majeure partie des terres des sept villages qui constituent le Pays d'Escornaix (entre Audenarde, Renaix et Grammont) est entre les mains de la population rurale avec une prédominance très nette de terres exploitées par les propriétaires eux-mêmes ; les terres données en fermage ne constituant que $35 \%$ de la superficie totale des villages. La majorité des exploitations (entre 76 et $91 \%$ ) sont inférieures à $5 \mathrm{ha}$. et les grandes fermes font presque complètement défaut. Au cours des $\mathrm{XVII}^{\mathrm{e}}$ et $\mathrm{XVIII}^{\circ}$ siècles cette situation subit quelques changements importants : les terres données en fermage s'accroissent de $15 \%$ environ mais si le nombre d'exploitations augmente, la superficie moyenne de celles-ci diminue considérablement. En même temps la participation des nobles et des bourgeois dans la propriété rurale devient plus importante.

Le second article est celui de $M$. K. Maddens ${ }^{72}$. Il a trait au village de Geluwe, situé en Flandre Occidentale. Cette étude très détaillée contient une quantité énorme d'informations qui auront leur importance pour les chercheurs futurs voulant se consacrer aux mêmes problèmes, c'est-à-dire à la propriété rurale. Il nous semble toutefois que son niveau n'est pas aussi élevé que celui du premier. Mais peut être est-il préférable d'en attendre la fin avant de conclure.

$M$. Robert Wellens, archiviste à Mons nous a fourni une étude très fouillée sur le domaine de Mariemont au Xvi ${ }^{0}$ siècle ${ }^{73}$. Cette contribution contient une foule de détails sur ce domaine royal qui connut un nouvel essor sous Marie de Hongrie qui y fit construire un pavillon de chasse. $M$. Wellens attache une attention toute particulière à la construction du château, à la description du domaine, puis à sa destruction et à sa reconstruction. Il est à regretter que l'auteur n'ait consacré qu'un nombre limité de lignes au fonctionnement économique du domaine et des fermes dépendantes. Cette remarque est également valable pour le chapitre sur les charbonnages de Morlanwelz-Mariemont.

Deux activités économiques du Pays de Liège ont été étudiées cette année : les charbonnages et la métallurgie.

L'histoire retirera fort peu de choses de la publication du $\mathbf{M}$. $\mathbf{R}$. Hankart intitulée Notes sur les charbonnages d'Avroy au Xvi ${ }^{\mathrm{c}}$ siècle ${ }^{74}$. Ce n'est ni un article, ni un inventaire. Il y fait mention de coutumes, de droit d'économie, de production et de contrat d'après les registres de la cour de justice d'Avroy au $\mathbf{x v I}^{\mathrm{e}}$ siècle. La documentation n'est pas dépourvue d'intérêt mais elle est très mal exploitée.

A M. G. Hansotte qui depuis plusieurs années déjà s'occupe de l'industrie métallurgique, nous devons un précieux relevé de quarante usines de la vallée de la Vesdre ${ }^{75}$. Ce sont des fenderies, des hauts fourneaux, des clouteries, des platineries, des laminoirs, des martinets, des forges ou des usines à canon. Pour chacune d'elles, l'auteur nous donne sa situation cadastrale et un petit historique qui nous conte

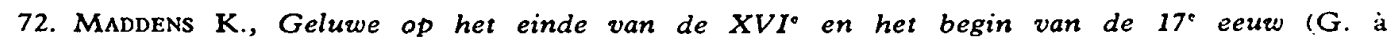
la fin du XVI' et au début du XVII' s.). Leiegouw, IV, 1962, pp. 103-116 (à suivre).

73. Wellens (R.), Le domaine de Mariemont au XVI' siècle (1546-1598). Ann. Cercle Archéol. de Mons, LXIV, 1962, pp. 79-172.

74. Bull. Inst. arch. liégeois, t. 76, 1962, pp. 45-90.

75. G. HANSOTTB, L'industrie métallurgique dans la vallée de la Vesdre aux temps modernes. Ibidem, t. 75, 1962, pp. 165-220. 
les vicissitudes de l'affaire depuis sa création jusqu'aux environs de 1830. Ce relevé est précédé d'une courte étude replaçant dans le cadre général de l'évolution industrielle liégeoise, l'industrialisation de la vallée de la Vesdre et caractérisant les modes de gestion les plus communément rencontrés : propriété familiale indivise et location pure et simple.

Par ailleurs, l'industrie métallurgique dans l'ancien marquisat de Franchimont a aussi retenu l'attention de $M$. Hansotte ${ }^{76}$. A une période d'expansion qui se situe dans la première moitié $\mathrm{du}^{\mathrm{xvI}}{ }^{\mathrm{e}}$ siècle et est due à la reconstruction des usines détruites par les Bourguignons, à l'industrialisation de la région et à une spécialisation nouvelle : la tôle martelée, succède une période de déclin. La diminution du nombre des fourneaux expliquée par l'expansion de la concurrence liégeoise et celle des platineries que provoque le protectionnisme des Pays-Bas et de la France de même que l'apparition au XVIII ${ }^{i}$ siècle des laminoirs, sont les raisons essentielles de cette évolution que l'auteur illustre par une liste des usines dont l'activité lui a permis d'écrire sa belle synthèse.

\section{L'évolution démographique}

Tandis que l'année passée les recherches de démographie historique avaient quelque peu marqué le pas, cette année peut être considérée comme une sorte de nouveau départ. Un premier recueil d'études d'histoire démographique et le premier livre qui traite, d'une façon concrète, de l'histoire de la population d'une ville belge ont en effet vu le jour.

Mentionnons en premier lieu le volume édité par le Crédit Communal de Belgique dans le cadre de ses activités "Pro Civitate» 77 . Cinq articles sont contenus dans ce recueil et il faut constater d'emblée que c'est l'histoire démographique de la Flandre Orientale qui y occupe la place la plus grande. Ce volume a entre autres le mérite de publier des travaux d'historiens professionnels et d'historiens amateurs.

La première étude, de Madame Van Assche-Van Cauwenbergh, s'intitule "Deux villages du Brabant sous l'Ancien Régime : Bierges et Overijse ${ }^{78}$. Bierges se trouve dans la partie francophone de la province tandis que Overijse se situe dans la partie flamande. Du point de vue économique la différence entre ces deux villages est très nette : tous les indices montrent que la situation économique et sociale fut nettement plus favorable à Bierges qu'à Overijse, ce qui ne fut pas sans influence sur l'évolution démographique. Mais les conclusions les plus intéressantes sont relatives au mouvement migratoire. A Bierges aussi bien qu'à Overijse le nombre des conjoints étrangers est peu élevé. $\mathrm{La}$ frontière linguistique a en outre joué un rôle considérable dans le choix même des conjoints, car l'on constate que dans les deux villages ceux-ci viennent en majeure partie du même côté de la frontière,

\footnotetext{
76. G. HANSOTTB, L'industrie métallurgique dans le bassin de la Hoègne aux temps modernes. Ibidem, t. 76,1963 , pp. 5-44.

77. Cinq études de démographie locale, Vijf bijdragen tot lokale demografie, vIII et 256 p. Bruxelles 1963 (Collection Histoire série in-8 ${ }^{\circ} . n^{\circ} 2$ ).

78. D. Van Assche-VAN CaUWenbergh, Deux villages du Brabant sous l'Ancien Régime : Bierges et Overijse. Etude de démographie historique, op. cit., pp. 9-66.
} 
celle-ci est donc une barrière culturelle aussi bien qu'une barrière démographique. Son invisibilité ne la rend pas moins réelle.

A l'abbé J. De Brouwer, dont les études sur le Pays d'Alost font autorité, l'on doit une contribution que l'on peut mettre en étroit rapport ${ }^{79}$ avec un de ses articles sur l'évolution sociale et économique dans le bailliage d'Erembodegem et dans la seigneurie d'OordegemSmetlede ${ }^{80}$. Il en ressort clairement que les effets des épidémies et des guerres de la seconde moitié du XVII ${ }^{\mathrm{e}}$ siècle sur le chiffre des populations ont été très limités et n'ont pas provoqué un recul notoire.

Pour ce qui est du $\mathrm{XvIII}^{\mathrm{e}}$ siècle l'accroissement de la première moitié du siècle dépasse en importance celui de la seconde. Cette évolution diffère largement de celle constatée dans les régions moins fertiles de la Flandre où l'industrie textile rurale était plus fortement implantée.

Dans son article ${ }^{81}, M$. A. De Vos s'est occupé de la petite ville d'Eeklo, située à l'ouest de Gand. Il retrace d'une manière exhaustive l'histoire démographique de ce petit centre où l'industrie textile fut toujours d'une grande importance. L'évolution du chiffre de la population et toutes les caractéristiques propres à cette évolution confirment entièrement les constatations qui ont été faites auparavant pour les communautés rurales où l'industrie linière occupait une position dominante. On peut résumer les conclusions de $M$. De Vos comme suit : après une très forte baisse causée par la guerre de la fin du Xvi siècle, la population s'est accrue considérablement durant la première moitié du XVII ${ }^{\mathrm{e}}$ siècle (de 2.000 en 1616-25 à 3.200 vers les années 1670). Au cours du XVIII siècle l'accroissement fut d'abord lent (jusqu'en 1750$60: 3.500)$, puis très important (5.400 vers 1795$)$. Pendant cette même période, couvrant les $\mathrm{XVII}^{\mathrm{e}}$ et $\mathrm{XVIII}^{\circ}$ siècles, les taux bruts de natalité et de nuptialité ont fortement diminué.

M. P. Deprez ${ }^{82}$ se consacre à l'analyse des recensements des années 1796/98 effectuées pour quatre villages de la même Flandre Orientale, villages situés dans la partie sablonneuse qui est en même temps la plus industrialisée de la province. Résumons ses conclusions : la situation démographique y est en général plus favorable que dans les villages de la partie fertile de la province : ce qui veut dire qu'à une détérioration de l'économie agraire (par suite de l'industrialisation) correspond une situation démographique favorable et inversement. La situation démographique de ces quatre villages se reflète dans une population considérablement plus jeune et dans un nombre d'enfants par ménage plus élevé. La situation agraire détériorée est confirmée par le fait que près de $50 \%$ de la population active est occupée dans l'industrie

79. J. DE BROUWER, De demografische evolutie in de meierij Erembodegem en de heerlijkheid Oordegem gedurende de XVII en XVIII' eeuw (l'évolution démographique dans le bailliage d'E. et la seigneurie d'O. aux XVII' et XVIII' siècles), op. cit., pp. 69-120.

80. J. DE Brouwer, Sociale toestand in de meierij Brembodegem en de heerlijkheid Oordegem in 1571 en de huidige evolutie (la situation sociale dans le bailliage d'E. et dans la

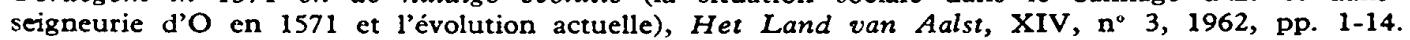

81. A. De Vos, De omvang en de evolutie van het Eeklose bevolkingscijfer tijdens de $X V I I^{\circ}$ en de $X V I I I^{\circ}$ eeuw (le volume et l'évolution du chiffre de la population d'Eeklo aux $\mathrm{XVII}^{\circ}$ et XVIII ${ }^{\circ}$ siecles), op. cit. pp. 123-148.

82. P. DePrez, De bevolking van Evergem, Knesselare, Ronsele en Zomergen in het licht van de volkstellingen van 1796-1798). (La population d'E., K., $R$. et $Z$. à la lumière des recensements de 1796-1798), op. cit., pp. 151-193. 
textile et que seulement $20 \%$ trouve un moyen d'existence dans l'agriculture.

La dernière étude est due à $M$. E. Hélin ${ }^{83}$. Elle concerne trois villages de l'actuelle province de Liège, situés à la limite du Pays de Herve : Chênée, Olne et Gemmenich. M. Hélin semble avoir eu pour but de fournir un modèle aux chercheurs locaux non familiarisés avec les problèmes de l'histoire démographique.

L'accent a été mis, peut-être un peu trop, sur des aspects d'ordre à notre avis secondaire (illégitimité et fluctuations mensuelles des naissances et des conceptions). La partie consacrée aux répercussions économiques de l'accroissement de la population est par contre très solide. Elle fait ressortir d'une façon remarquable la structure particulière de la vie économique. L'extension des herbages et la diminution des terres labourables ont eu pour conséquences fâcheuses une paupérisation et une industrialisation poussée.

Si cette contribution de $M$. Hélin ne nous satisfait pas entièrement, il y va tout autrement de son ouvrage sur la population liégeoise ${ }^{84}$. Ce n'est pas son premier livre sur la population de la Cité Ardente, mais on doit considérer ses publications antérieures comme des travaux préparatoires ${ }^{85}$. L'étude de $M$. Hélin est le premier volume relatif à l'évolution démographique d'une des grandes villes de Belgique, ce qui est déjà en soi une grande réalisation. De plus un grand nombre de ses conclusions et de ses constatations sont très importantes. En premier lieu : l'évolution du chiffre de la population. Celui-ci était d'environ 20.000 à la fin du Moyen Age, deux siècles plus tard, il avait fortement augmenté : entre 1650 et 175044.000 à 57.000. Vers la fin du $\mathrm{XVIII}^{\mathrm{e}}$ siècle cependant il était en régression.

Si les données concernant l'évolution du chiffre de la population liégeoise sont rares, ceci est principalement dû au fait que pour la période antérieure à 1790 aucune évaluation correcte de la population n'a été faite. L'étude critique de ces évaluations et l'analyse de l'évolution démographique sont traitées dans un premier chapitre.

Le second est entièrement consacré à quelques structures démographiques telles : rapport communiants-population globale, répartition de la population selon l'âge, excédents féminins, répartition selon l'état matrimonial et les dimensions des ménages. Il est à noter qu'il y a des concordances, maintes fois frappantes, entre les constatations pour Liège et celles faites pour les villes de Malines, Anvers, Gand et Bruges.

Dans le dernier chapitre, $\mathbf{M}$. Hélin traite de divers aspects relatifs à la natalité et à la mortalité. Il en résulte que durant tout le $\mathrm{XVIII}^{\mathrm{e}}$ siècle les différences sociales n'ont pas provoqué des variations dans la fécondité et que la natalité illégitime a fortement progressé, tandis que la mortalité infantile restait très élevée : 247,7 pour mille.

83. E. HELIN, Croissance démographique et transformation des campagnes : Chênée, Olne et Gemmenich aux $X_{V I I I^{\circ}}$ et XIX' siècles, op. cit., pp. 195-240.

84. E. HÉln, La démographie de Liège aux XVII et XVIII' siècles. Académie Royale de Belgique, Classe des Lettres et des Sciences morales et politiques, Mémoires, collection in-8 ${ }^{\circ}$, t. LVI, fasc. 4, Bruxelles, 1963, 282 p., ill.

85. Entre autres, La population àes paroisses liégeoises aux XVII et XVIII $I^{\circ}$ siècles et Les Capitations liégeoises. 
Tout au long de son étude et c'est là je crois un des grands mérites de son livre, $M$. Hélin a mis en évidence les différences entre les paroisses de la Cité et celles des faubourgs. Ses conclusions rejoignent sur presque tous les points celles de feu Blockmans, MM. Van Werveke et Deprez.

De l'article de $M$. De Rammelaere sur le village de Kanegem ${ }^{86}$, contigu à la petite ville de Tielt, il ressort que durant le Xvir $^{\circ}$ siècle la population a fortement augmenté puis a connu une stagnation jusque vers 1740 puis de nouveau un accroissement. Remarquons que l'auteur n'a pas utilisé les chiffres des décès et des mariages. Dans le premier cas il s'est basé sur les affirmations antérieures pas toujours très convaincantes selon lesquelles les chiffres de décès sont incomplets. Une analyse de la valeur des registres paroissiaux eût été préférable. Quant aux totaux annuels des mariages, il est vrai qu'ils n'ont guère de valeur pour le calcul du chiffre de la population d'une petite localité comme Kanegem.

Et ceci vaut également pour l'article de $M$. A. Wyffels sur Tielt ${ }^{87}$. Mais il faut penser aux recherches futures, car lorsque l'on disposera de nombreuses analyses, les taux de nuptialité et les totaux annuels des mariages auront leur importance. C'est pourquoi les études, même strictement locales, doivent apporter ce genre de renseignements.

A côté de cette série de publications se rapportant à l'histoire démographique de la Belgique du XVI ${ }^{e}$ au XIX ${ }^{e}$ siècle, citons une étude de $M$. J. Verbesselt sur les couches de la population à Asse de 1320 à $1450^{88}$. L'auteur s'est basé sur les censiers provenant de l'administration du domaine ducal au Brabant. Après une analyse de la valeur et des différentes caractéristiques des sources utilisées, l'auteur se penche sur les informations contenues qui sont : données généalogiques, professions exercées à Asse de 1320 à 1450, bourgeois et censitaires. Reste à noter que l'auteur ne nous fournit que des listes de noms. Mais comme $M$. Verbesselt le souligne, ces listes, et plus spécialement celles des gens redevables d'un cens aux receveurs ducaux, fournissent pour ainsi dire le nombre complet des habitants d'Asse au Moyen Age.

\section{Les églises}

M. Gérard Moreau, chef de travaux à l'université de Liège et élève du professeur L. E. Halkin vient de publier une histoire du protestantisme à Tournai jusqu'en $1565^{89}$.

La première partie de son livre comprend le récit des faits, la seconde est constituée par une liste chronologique et une notice bio-

86. DE RAMmELAERE C., Kaneghem gedurende de $18^{\circ}$ eeuw. Bijdrage tot de demagrafische en sociaal-ekonomische plattelandsgeschiedenis (K. au $18^{\circ} \mathrm{s}$. Etude d'histoire démographique et économico-sociale du plat-pays). De Leiegouw, IV, 1962, pp. 189-203.

87. Wypfels A., De evolutie van het Tieltse bevolkingscijfer in de $17^{\circ}$ en $18^{\circ}$ eeuw (1'évolution de la population de Tielt aux XVII ${ }^{\circ}$ et $X$ XIII $^{\circ}$ siècles). Leiegouw, III, 1961, $n^{\circ} 2$, pp. 213-227.

88. Verbesselt J., De bevolkingslagen van Asse vanaf 1320 tot 1450 . (Les couches de la population d'Asse de 1320 jusqu'à 1450). Eigen Schoon en De Brabander, XLV, 11-12, 1962, pp. $389-417$ (à suivre).

89. G. Moreau, Histoire du Protestantisme à Tournai jusqu'à la veille de la Révolution des Pays-Bes. Bibl. de la Fac. de Phil. et Lettres de l'Un. de Liège. Fasc. CLXVII, Paris, 1962. 
graphique de toutes les personnes poursuivies pour fait de religion. C'est au moment où Tournai fut annexé aux Pays-Bas que la réforme protestante y apparut. Dès avant 1530, une communauté s'y organisa. A partir des années 1541-42 la secte libertine, apparentée à l'anabaptisme, y sema la discorde. La publication du livre de Calvin sur « ce que doit faire un homme fidèle quand il est entre les papistes » fit croître leur désarroi. Pierre Bruly, disciple direct de Calvin, vint à Tournai et réussit à transformer la communauté réformée en une église calviniste. Toutefois une petite secte baptiste comptait près de 15.000 membres, soit plus de la moitié de la population. La première manifestation publique se déroula les 29 et 30 septembre 1561. La répression fut brutale. Pendant l'été de 1562 les calvinistes réussirent à organiser des prêches en dehors de la ville. A la veille du soulèvement général de 1556, l'église protestante de Tournai, dirigée par des chefs d'une qualité exceptionnelle, était la citadelle la plus solide du calvinisme dans la partie wallonne des Pays-Bas.

Si les partisans ont été recrutés dans toutes les classes sociales, tant parmi les artisans pauvres, que parmi les représentants du capitalisme, il faut toutefois remarquer que les membres des classes dirigeantes ont pu dans une très large mesure échapper à l'application des peines prévues par les placards. Les fondeurs, les sayetteurs, les couturiers, les ouvriers, les " jeunes compagnons », les « mauvais garçons » et les «femmes du peuple » furent seuls à monter à l'échafaud.

Depuis quelques années, on est un peu mieux informé de l'importance numérique des calvinistes dans quelques grandes villes, surtout à Anvers et à Tournai. C'est maintenant le cas aussi pour Gand. Ils n'y formaient pas une minorité turbulente recrutée parmi les couches les plus déshéritées de la population mais au contraire une forte minorité, bien représentée dans tous les groupes sociaux moins peut-être parmi ceux qui travaillaient à bon marché que chez les artisans des corporations et les marchands. Il ressort d'un article, consacré à la pénétration du calvinisme dans les diverses couches de la population gantoise par un jeune historien, $M$. Delmotte ${ }^{90}$, que telle était déjà la situation à l'époque de l'iconoclasme (1566). A l'aide des comptes rendus d'interrogatoires organisés par le magistrat de la ville, à la veille des désordres, l'auteur a pu établir que rares étaient ceux qui étaient prêts à défendre, en cas de nécessité, les biens du clergé. En prenant appui sur des listes de briseurs d'images qu'il a établies lui-même et de calvinistes convaincus, classés d'après leur degré de fortune (à l'aide des comptes des confiscations), $M$. Delmotte démontre qu'il serait erroné de confondre la foule des iconoclastes avec les calvinistes convaincus. Les briseurs d'images étaient surtout de pauvres gens révoltés, tandis que le calvinisme trouvait ses adeptes dans toutes les couches de la société.

Par ailleurs le professeur Paul Harsin a fait une communication sur * Les premières manifestations de la réforme luthérienne dans le diocèse de Liège 1520-1530 ». qui est publiée dans le Bulletin de l'académie royale de Belgique ${ }^{91}$.

90. M. DELMOTTE, Het calvinisme in de verschillende bevolkingslagen te Gent (1566-1567). Tijdschrift voor Geschiedenis, 76, Groningue, 1963, pp. 145-176.

91. Classe des lettres, $5^{\circ}$ série, t. XLVIII, Bruxelles, 1962, pp. 273-294. 
Après avoir examiné les diverses régions du diocèse, particulièrement étendu à ce moment, il conclut que ce n'est guère avant les années 1525-1526 que les idées luthériennes prennent racine dans les parties excentriques du diocèse (Louvain, Aix, Berg-op-Zoom, Bois-le-Duc, Bréda). Il faut attendre l'année 1530 pour trouver les premiers cas d'hérésie avérés dans la principauté liégeoise où, rappelons-le, le pouvoir de l'évêque et l'autorité du prince se confondent en une seule personne : Erard de la Marck.

A l'occasion d'un procès de nomination d'un évêque auxiliaire de Liège au XVII ${ }^{\circ}$ siècle, $M$. J. Hoyoux ${ }^{92}$ relève que sous les apparences de la plus stricte régularité l'enquête du nonce fut faussée de façon à imposer aux Liégeois un protégé des Colonais et du nonce Chigi, futur Alexandre VII.

\section{Les justices, les soldats}

Il existe dans les coutumes de Flandre une institution, qui porte le nom de Houdenisse, relative aux droits et aux devoirs du père ou de la mère vis-à-vis de ses enfants, après son veuvage. Dans un gros article fort bien documenté, M. J. Gilissen ${ }^{93}$, montre qu'on trouve cette institution partout en Flandre du $\mathrm{XIV}^{\mathrm{e}}$ au $\mathrm{XVIII}^{\mathrm{e}}$ siècle, sauf à Termonde et dans la Flandre Gallicante. Il explique ensuite sa nature et ses caractéristiques dont les principales se rapportent à l'administration des biens et au contrôle des revenus. Au cours de son exposé centré sur des textes modernes, il rapproche l'institution flamande de deux formes parisienne et artésienne connues sons le nom de garde bourgeoise et de bail. Après s'être demandé laquelle a pu influencer l'autre, avec une prudence, dont on ne peut que le louer, il propose une enquête plus approfondie des sources des $\mathrm{XII}^{\mathrm{e}}$ et $\mathrm{XIII}^{\mathrm{e}}$ siècles, avant de donner une réponse définitive.

La franche forêt de Meerdael appartient au seigneur d'Aerschot depuis 1284. M. De Fraine, qui prépare un travail sur la cour de justice de cette forêt nous donne ${ }^{94}$ comme Vorarbeit quelques indications sur l'établissement, la compétence et le fonctionnement de cette juridiction aux XVII $^{\mathrm{e}}$ et $\mathrm{XVIII}^{\mathrm{e}}$ siècles. On se demande pourquoi le sous titre de son article dit qu'il s'agit d'un exposé introductif ?

De son côté, M. R. Van der Made publie dans le Bulletin des anciennes lois et ordonnances vingt-cing textes de jugement provenant des registres des échevins de Clermont et de Hermalle-sous-Huy ${ }^{95}$. Il s'agit d'actes relatifs à des biens ruraux sur lesquels on a assigné des rentes ou qu'on a grevé de charges. Des conflits de compétence entre cours échevinales et des questions relatives à des droits de succession, à des coups, à des baux ou à des emprunts leur sont soumis. Ce petit recueil de jurisprudence est utile. Il le serait plus encore si les analyses

92. J. Hoyoux, Procès de nomination de fean-Antoine Blavier, évêque-suffragant de Liège (1654-1699). Bull. Inst. Hist. belg. Rome, t. 35, 1963, pp. 273-289.

93. J. GIIISSEN, De houdenisse in het oud-Vlaamse recht. Revue d'hist. du droit, t. 31, 1963, pp. $346-402$.

94. P. DE FRAINE, Het woudgerecht van het vrijwoud van Meerdaal (Inleirdende archiefstudie). Anciens Pays et Assemblées d'Etat, t. 27, 1963, pp. 125-162.

95. R. VAN DER MADE, fugements de la Haute Cour de justice du han de Clermont en Condroz (1468-1573). Bull. Com. An. Lois et ordonnances, t. 20, 1961-62, pp. 451-520. 
qui précèdent la publication des actes contenaient moins de termes régionaux tels que rendage, herdage, vesture, command, déminement, etc...

Dans les registres de l'échevinage de Bruges, $M$. Schouteet n'a trouvé que quinze jugements condamnant des gens de métiers pour les années 1521-1550. Ils les publie ${ }^{96}$ avec une petite introduction mais hélas sans index de personnes ni de choses.

Les régiments nationaux dans les Pays-Bas Autrichiens sont à l'honneur grâce à une édition de textes due à $\mathbf{M}$. J. Ruwet, professeur à l'Université de Louvain et précédée d'une très importante introduction ${ }^{97}$. Les effectifs de ces régiments permanents et composés de volontaires rémunérés, connurent une évolution remarquable : de 20.000 hommes en 1701, ils tombent à 4.155 en 1726, pour atteindre de nouveau 17.000 à la fin du siècle. Si le recrutement ne s'opérait jamais facilement, les autorités devaient en outre lutter contre la plaie générale de la désertion. En tenant compte de la densité de la population le Luxembourg et le Namurois fournissaient (par intérêt et nécessité) le plus grand pourcentage des soldats. En chiffres absolus le Brabant est eh tête avec $30 \%$, suivi de la Flandre avec $26 \%$. La plupart des soldats $(2 / 3)$ étaient de pauvres diables, sans éducation, venant en majorité des villes.

\section{L'EPOQUE CONTEMPORAINE}

\section{Sous la République et l'Empire}

C'est l'histoire religieuse qui a bénéficié le plus de l'activité des historiens pour la période française.

M. L. Preneel ${ }^{98}$ a étudié la réorganisation des diocèses en Belgique sous le Consulat, en plaçant son sujet dans le cadre général des négociations et des pourparlers entre le gouvernement français et le SaintSiège. De cette étude on peut conclure que, par la réduction du nombre des évêchés au strict minimum, Bonaparte a réalisé complètement ses propres desseins, que le premier consul a toujours pris l'initiative et a réussi sans cesse à imposer sa volonté à Pie VII et que la Belgique a bénéficié de l'attribution de deux évêchés supplémentaires.

$M$. F. Jacques a publié une étude ${ }^{99}$ sur la situation de l'Eglise dans la ville de Namur et dans sa banlieue après la Révolution. En premier lieu, l'auteur rappelle les circonstances des négociations du Concordat, les étapes du rétablissement du culte catholique dans le diocèse et les phases successives de la mise en application des dispositions concordaires. Il nous donne ensuite dans l'ordre alphabétique des succursales, annexes et dépendances, une notice historique des circonscriptions. Il 450.

96. A. SchouteEt, furidictie over ambachtslieden te Brugge in de 16 eeuw. Ibidem, pp. 403-

97. J. RUweT, Soldats des régiments régionaux au XVIII* siècle, Bruxelles, 1962, C.R.H., in-8`, 312 p.

98. L. Preneel, Bonaparte, le concordat et les nouveaux diocèses en Belgique. Rev. Hist. eccl. t. 57, 1962, pp. 871-900.

99. F. JACQUES, Le rétablissement du culte ca:holique à Namur après la Révolution, 1 vol. Gembloux, 1963. 
ressort de cette enquête que le découpage paroissial actuel de la ville et de sa banlieue a été créé essentiellement par Mgr Pisani de la Gaude et mis en vigueur le 5 juillet 1805 pour les paroisses de NamurVille, le $1^{\text {er }}$ octobre 1808 pour l'ensemble du diocèse.

Par ailleurs C. De Clercq ${ }^{100}$ a consacré un article aux prêtres de l'arrondissement de Malmédy soumis et insoumis à la loi du 21 nivôse an VIII (= 11 janvier 1800) qui réclamait un serment de fidélité à la Constitution. Prenant comme source et publiant « l'Etat nominatif des prêtres du second arrondissement »dressé le 23 vendémiaire an XI par le sous-préfet de Malmédy, l'auteur constate que les religieux soumis sont en large majorité et qu'il y avait chez les Capucins une forte et chez les Bénédictins et les Récollets une petite minorité d'insoumis.

De son côté $M$. A. Fabri 101 nous donne, à l'aide du registre paroissial de Cens et du récit de P. L. Antoine (curé d'Erneuville de 1793 à 1809), un aperçu des persécutions au canton de La Roche sous le Directoire. Il traite successivement de la situation à la fin de l'ancien régime, du refus des prêtres de prêter le serment de haine à la royauté, des réactions du gouvernement qui s'en suivirent en 1798 et 1799 et de la mise en application du Concordat.

L'article sur le Stévinisme à Wavre de M. J. Soille ${ }^{102}$ apporte une bonne contribution à la connaissance des origines de l'opposition au Concordat dans une région où l'influence de Stévens se fit grandement sentir et où se cristallisa l'opposition du clergé. Il expose l'idée que cette opposition est née avec la promulgation, comme annexe au Concordat, des articles organiques qui reprenaient en grande partie à l'Eglise ce qui venait de lui être concédé. L'auteur conclut que Wavre était le principal foyer du stévinisme, que le nombre des adhérents n'était pas aussi minime que le dit un rapport confidentiel de souspréfet au préfet de la Dyle et que les stévinistes de Wavre tout en étant de farouches adversaires du serment de haine et des articles organiques n'avaient jamais nié la légitimité du Concordat et des évếques concordataires.

Parmi les soulèvements paysans de $1798, \mathrm{G}$. Trausch attire notre attention sur une révolte à Neufchâteau ${ }^{103}$. Révolte peu grave, mais l'auteur en profite pour remarquer que le mécontentement se manifestait dans une région francophone du Luxembourg et qu'il y avait désaccord important parmi les autorités républicaines locales.

Prenant comme sources principales quelques témoignages oculaires et deux listes de noms de rebelles et de suspects, dressées par le commissaire du canton de Sleydinghe à la demande de l'administrateur près le département de l'Escaut à Gand, M. Ryckaert ${ }^{104}$ nous donne un

100. C. DE ClercQ, Prêtres soumis et insoumis dans l'arrondisscment de Malméciy en 1801. Tablettes d'Ardenne et Eifel, I, 1961, I, pp. 143-287.

101. A. FABRI. Episodes de la persécution sous le Directoire d'après le registre paroissial de Cens (1787-1819). Ardenne et Famenne, V, 1962, I, pp. 14-22, 2, pp. 63-74.

102. J. SonLE, Le « Stévinisme $»$ dans la région de Wavre. Wavriensia, XI, 1962, 2, pp. $17-55$.

103. G. TRAUSCH, De nouveau sur le Kleppelkrich»: Les soulèvements paysans de 1798 dans la région de Neufchâteau et leurs répercussions dans le Département des Forêts. Publications de la Section Historique de l'Institut G.-D. de Luxembourg, LXXIX, 1962, pp. 63-135. 104. RYCKAZRT (M.). De opstand der bevolking tegen het Frans Bewind te Zomergem, Sleiairlge on Waar.choo: op den $1^{\circ}$ en $2^{\circ}$ Brumaire (23 en 24 october 1799). Appeltjas van het Mceticsland, XIII, 1962, pp. 181-198. 
aperçu de la révolte contre le gouvernement français des 23 et 24 octobre 1799 à Somerghem, Sleydinghe et Waerschoot. Il constate que la plupart des hommes arrêtés étaient étrangers aux communes mentionnées qui ont été néanmoins gravement punies.

A l'aide des recettes et des dépenses communales, R. Darquenne ${ }^{105}$ a brossé une esquisse de la situation générale et de la politique communale de la ville de Tournai sous le Consulat et l'Empire. Il résulte de cette étude que durant cette période les budgets, qui étaient auparavant toujours déficitaires, se soldèrent en boni, que l'augmentation des recettes se doubla d'une majoration parallèle des dépenses, que les retenues imposées par le gouvernement ne cessèrent de croître et que l'administration fit de son mieux pour moderniser la ville.

Pour beaucoup de Flamands, le personnage de Bakelandt reste un souvenir de lecture de jeunesse, lié à un livre populaire quasi-historique, où la bravoure et la rudesse cyniques alternaient parfois avec un petit trait sympathique de vagabondage romantique. Mais ce Louis Bakelandt et sa bande de Vrijbos sont des réalités historiques, que le professeur Strubbe (en collaboration avec E. Hosten) avait déjà étudiées en 1927. Après de multiples randonnées, des meurtres et des vols, la bande de Bakelandt a été jugée et finalement exécutée à Bruges en 1803, peine assez lourde, expression de la volonté de répression du banditisme. Cet épisode historique, typique mais néanmoins sans portée générale a continué à intriguer le public et a été source d'une série de romans, de poèmes et de pièces de théâtre. Dans un exposé, qui intéressera autant l'historien que le folkloriste, le professeur Strubbe montre l'évolution remarquable du personnage de Bakelandt dans la littérature jusqu'à nos jours ${ }^{106}$. Dès 1803, Bakelandt fut représenté comme un escroc corrompu. Huys vers 1850 accentua son manque de religion, ce qui menaçait la pureté des mœurs des Flamands. Puis Bakelandt fut transformé en partisan de Proudhon et d'un socialisme utopique. Pour Planquaert, en 1882, il était un républicain, traitre au peuple flamand. Si en 1923 il est pour ainsi dire le héros d'un roman de détective, en 1954 il fait figure d'Al Capone à la mode d'Hollywood, pour devenir assez curieusement un blouson noir moderne dans une œuvre du célèbre littérateur flamand Herman Teirlinck.

\section{La pensée et l'action politiques}

L'influence de Lamennais dans la pensée politique et religieuse de l'Europe Occidentale du $\mathrm{XIX}^{\ominus}$ siècle ne peut être niée. Le nombre des publications consacrées au personnage devient démesuré. En Belgique il faut également en tenir compte : trop souvent il fut le sujet d'âpres discussions politiques, de polémiques dans la presse et il faillit même faire échouer d'importantes initiatives du clergé : la fondation de l'université de Louvain par exemple. Souvent aussi il fut le point de mire

\footnotetext{
105. DARQuenne (R.), L'activité du Conseil municipal de Tournai sous le Consulat et l'Empire. La Vie Wallonn=, XXXVI, 1962, pp. 235-263.

106. E. I. STRUBBE, De metamorfoses van de Bakelandt-figuur (1803-1961), Volkskunde, 1963, pp. 158-173.
} 
des réactions de Léopold I et de Metternich. Les historiens ne sont d'ailleurs pas d'accord sur l'importance du rôle qu'il joua en Belgique. Pirenne et Terlinden acceptent une influence directe, la génération nouvelle, avec en tête le Professeur Haag, a un jugement plus nuancé. Mgr Simon joue un rôle de premier plan dans cette polémique. Plusieurs de ses articles ont déjà traité du personnage passionnant que fut Lamennais. La dernière en date de ses publications - il s'agit cncore de la position du problème et non d'une solution définitive - indique la nouvelle voie suivie. Le titre même du livre en dit long ${ }^{107}$. Après « une brève mais substantielle analyse des idées et du caractère du maître de la Chênaie », Mgr Simon en définit ainsi la principale caractéristique : "en l'âme et la doctrine de Lamennais confluent les courants divers $\mathrm{du} \mathrm{XIX}^{\ominus}$ siècle, mais également les impulsions d'un tempérament personnel individualisant, de perceptions synthétiques rationalistes, de nécessités sociales et d'une croyance en un Dieu providentiel ». Ces idées reçurent bon accueil dans les milieux les plus divers de la Belgique. Certains $y$ cherchèrent un repère idéologique, d'autres y trouvèrent l'affirmation de leur attitude politique déjà élaborée mais aux contours encore indécis. Comme tel il ne créa pas l'unionisme, mais il donna plus de force à ce mouvement. Son influence dans l'élaboration de la constitution se fit plutôt sentir dans l'esprit, qui y présida, que dans les idées exprimées. Après la condamnation par «Mirari Vos» et «Singulari Nos», les nonces, le roi, les ultramontains et le secrétaire d'Etat ont toujours confondu les deux tendances du mouvement. Et pourtant, ce fut ce climat qui permit la création d'une union catholico-libérale et empêcha, par l'attachement à la constitution et aux libertés libérales, la création d'un parti catholique. Il est certain que les idées de Lamennais survécurent en cachette au cœur de l'université de Louvain. En quête d'une philosophie catholique, $\mathbf{M g r}$ Descamps et son disciple Mgr Mercier s'inspirèrent souvent de lui et quelques expressions de politiciens renommés comme un De Decker ou un Vilain XIII se rattachent à la pensée du prêtre malouin. Son programme social d'autre part n'a pas trouvé d'audience. L'auteur conclut en nous proposant une nouvelle perspective : " influence ou rencontre mennaisienne? Le problème ne devrait-il pas être posé autrement? Ne pourrait-on pas se demander si la Belgique contemporaine n'est pas une des meilleures réalisations des idées défendues naguère par Lamennais? La réponse me paraît devoir être affirmative ».

Une autre étude du même auteur ressemble assez fort à la précédente ${ }^{108}$. C'est de nouveau, l'unionisme qui en est le problème-clef. Mais ici Mgr Simon essaie d'en étudier l'essence par une voie différente. Le point de vue de Rome, qui s'extériorise startout dans les missives du secrétaire d'Etat, constitue ici la source principale. Sous Capacinni on ne voulait point de cette alliance monstrueuse. En effet, cet unionisme

107. A. Simon, Rencontres Mennaisiennes en Belgique. 1 vol. Bruxelles, 1963, 268 p. (Académie Royale de Belgique, Cl. Lett. Sc. Mor. et Pol., Mémoires, Coll. in- $8^{\circ}$, t. LVI, fasc. 3).

108. A. Simon, Le Saint-Siège et l'union catholico-libérale (1828-1846). Bull. Instit. Hist. helge de Rome, XXXIV, 1962, pp. 595-616. 
portait en soi les germes d'un mouvement révolutionnaire et d'après la conception en vigueur, on ne pouvait attaquer l'autorité royale. La monarchie de droit divin s'imposait encore. Le texte de la bulle "Mirari Vos » apporte un élément nouveau. A tort ou à raison, le Vatican était convaincu que Lammenais avait de l'influence en Belgique. La peur de l'indifférentisme et du relativisme, que cette attitude pouvait susciter parmi les catholiques, en fut le thème central. En 1846 pourtant Rome accepta inconditionnellement l'unionisme. La peur d'une poussée du libéralisme radical, incita même à modérer le zèle ultramontain. De ces attitudes variables, il ressort que Rome supposait que l'Union avait une doctrine sous-jacente.

Même après la disparition des ministères unionistes, certains Flamands ont cherché un terrain d'entente où un dialogue entre les différents partis fût possible. M. Wils ${ }^{109}$ croit retrouver dans la création, au cours des années 60, d'un « Onafhankelijke Volkspartij » (Parti Populaire Indépendant) une semblable tendance. Le centre de ralliement fut constitué par le « Nederduitsche Bond »(le parti thiois) où les flamingants tant libéraux que catholiques pouvaient se rencontrer. A Bruxelles, J. Hoste dans son journal « de Zweep » ne cachait pas ses sympathies pour le mouvement, tandis qu'à Bruges des cercles progressistes et particulièrement "de Klauwaerts » sous l'impulsion d'Emile Moyson y collaboraient activement. Le cercle créé à Gand autour de J. Vuylsteke adhérait également à ce programme. Ce parti d'une composition hétérogène, mais où l'élément catholique prédominait, périclita par suite d'âpres discussions au sujet de l'influence de l'église qui surgirent sous le ministère de Rogier. L'auteur croit que l'existence de ce parti, avec un programme si radical, prouve que le mouvement flamand dans son activité ne s'est pas borné exclusivement à la question linguistique. Quant au parti lui-même il a contribué indéniablement au développement des idées démocratiques.

L'historien de la Belgique contemporaine dispose maintenant d'un excellent instrument pour repérer les papiers d'hommes d'Etat belges. C'est à $M$. Haag ${ }^{110}$ que l'on doit ce guide qui signale non seulement les papiers conservés mais encore le lieu où ils se trouvent et les conditions requises pour en obtenir communication.

L'ouvrage de Brison D. Gooch ${ }^{111}$ sur les journées mouvementées de 1848 ne paraît pas mériter un jugement très favorable. Dans son exposé, l'auteur procède de la façon suivante : après une courte analyse de la situation - tant à l'intérieur qu'à l'extérieur de notre pays - peu avant 1848, il relève les réactions face à la révolution de Paris. Cette dernière provoque en Belgique une grande confusion et un sentiment d'insécurité. Le roi offre sa démission, les ministres et le pays entier sont en plein désarroi. L'intervention commune et énergique des différents partis

109. L. WILs, Tussen taalstrijd en arbeidersbeweging : de Onafhankelijke Volkspartij in de jaren 1860. - Bijdragen tot de geschiedenis inzonderheid van het oud hertogdom Brabant. $3^{\circ}$ reeks, deel 13 , afl. 4,1961 , pp. 147-184.

110. H. HAAG, Les archives personnelles des anciens ministres belges, 1 vol. 35 p. in-8', Louvain-Paris 1963. (Centre Interuniversitaire d'histoire contemporaine, cahier 29). p. 110 .

11. BRISON D. Gooch, Belgium ant the February Revolution, Den Haag, M. Nijhoff, 1963, 
évite la confusion générale. Les groupements républicains et démocratiques - l'auteur les nomme à tort « the communists 》- sont trop faibles et trop désunis pour déclencher un soulèvement. Finalement l'auteur analyse au jour le jour toutes les activités diplomatiques qui se déroulent en Belgique et dans les pays limitrophes jusqu'au mois de juin 1848.

Tant qu'il s'en tient à la synthèse systématique et chronologique des différents rapports diplomatiques, l'auteur nous séduit. Mais lorsqu'il fait l'analyse des situations et des réactions intérieures on a tôt fait de déceler les grandes lacunes que présente son information. Les nombreuses et excellentes études, traitant de l'année 1848 ont clairement et nettement démontré qu'il ne suffit pas de s'en tenir aux comptes rendus des gouverneurs pour connaître la force de la tension. Il faut reconnaître à $M$. Gooch, professeur d'histoire à l'université d'Oklahoma, une grande objectivité dans la relation des faits, mais la situation intérieure extrêmement confuse de même que les répercussions de la révolution parisienne sur le développement ultérieur de la Belgique ne sont pas suffisamment mises en relief.

V. Mallinson 112 propose dans son livre "Power and Politics in Belgian Education (1815-1961) » une esquisse de l'histoire de l'enseignement en Belgique. Il expose dans une première partie la politique des différents ministères à propos de l'enseignement ainsi que la genèse du système d'enseignement actuellement en vigueur en Belgique. Il envisage toutes les sortes d'enseignement tels que le primaire, le secondaire, le normal, le technique, le commercial et l'universitaire tant officiels que catholiques. Son attention est aussi attirée par la Ligue de l'Enseignement et par d'autres institutions dues à l'initiative privée de certains pédagogues ainsi qu'au mouvement flamand et à la flamandisation de l'université de Gand. Dans une deuxième partie l'auteur tente de définir les facteurs économiques qui ont influencé notre enseignement. Un dernier chapitre enfin est consacré à l'enseignement dans ce qui fut le Congo belge et à l'enseignement colonial en Belgique.

Le complot orangiste d'Anvers du 25 mars 1831 a fait l'objet d'un article fort bien documenté de L. Leconte ${ }^{113}$. L'intérêt de cette étude est évident. On y apprend le rôle joué par le gouverneur militaire d'Anvers, le général Vander Smissen (déjà auparavant suspect de duplicité) figure centrale de la conspiration qui tenta de dissoudre le ministère et de placer le prince héritier des Pays-Bas, Guillaume d'Orange, sur le trône de Belgique.

\section{Les structures sociales et les mouvements ouvriers}

A côté d'inventaires d'archives, de répertoires de périodiques, d'éditions de documents statistiques, le Centre Interuniversitaire d'Histoire Contemporaine publie aussi des cahiers auxquels on pourrait donner le titre : "A la recherche des structures sociales ». Notons dans

\footnotetext{
112. V. Mat.xinson, Power and Politics in Belgian Education (1815-1961), London, Heinemann Educational Books Ltd., 1963, 253 p.

113. L. Leconte, Souvenirs du Complot Orangiste d'Anvers le 25 mars 1831. Carnet de La Fourragère, XIV, 1962, 7, pp. 451-481.
} 
ce cadre une contribution de $\mathbf{M}^{11 \mathrm{e}}$ Vervaeck ${ }^{114}$ concernant quelques sources de la période française. Cette publication n'est pas un inventaire de tout ce qu'on peut trouver à ce sujet, mais elle donne au moins quelques exemples pour chaque groupe de sources.

Une grande partie de l'étude est consacrée aux contributions, y compris les emprunts forcés, la contribution de guerre de 1794 et les listes des plus imposés. Elle est suivie de renseignements sur les notables, la « Garde nationale », etc. pour finir avec les listes et les recensements de population. De très bons indices rendent de grands services surtout celui des sujets et des mots-matière.

Dans l'article de $\mathbf{M}$. Delbaere ${ }^{115}$, on retrouve la même orientation Il classe les sources d'histoire sociale de la ville de Gand d'après les grands problèmes : généalogie, fortune, activités économiques et politiques. D'une part, c'est un inventaire avec analyse des documents - c'est le cas par exemple pour les registres de population, les listes d'électeurs, les dossiers d'installations dangereuses et insalubres d'autre part l'auteur a essayé de classifier les plus imposés et les électeurs selon les groupes professionnels et suggère des méthodes de travail à ce sujet.

A travers les travaux du père $K$. van Isacker on constate une évolution très marquée. Au départ il s'était consacré à l'histoire du parti catholique. Maintenant il étudie l'histoire du syndicalisme, catholique, certes, mais en réalité plus syndicaliste que catholique. Ce point d'aboutissement, peut-être provisoire, se révèle très nettement dans deux travaux récents sur les ouvriers du port d'Anvers ${ }^{116}$ qui se complètent d'ailleurs.

La tâche n'était pas simple. Quoi qu'en pensent les médiévistes, il est plus difficile d'écrire une étude sur les syndicats du $\mathrm{XrX}^{\mathrm{e}}$ siècle que sur les corporations du $\mathrm{xv}^{\circ}$. Car pour le début du syndicalisme les sources sont extraordinairement rares et pauvres et il faut recueillir les renseignements un à un à travers un immense fouillis. Le docker anversois d'avant la première guerre mondiale n'avait pas la vie facile. De longues heures de travail, de bas salaires concurrencés par le travail des femmes et des enfants, des tâches difficiles et malsaines, une insécurité continuelle, tel était son lot. Il faut ajouter que tout ouvrier non qualifié pouvait trouver du travail à condition d'avoir la constitution physique nécessaire. Il en résulta que l'offre dépassa de beaucoup la demande. L'extension systématique et continue des complexes portuaires n'apporta ici aucun changement car la diminution de la réserve fut comblée aussi vite par des éléments venus de la campagne environnante grâce à l'amélioration des chemins de fer vicinaux. Cette situation fut exploitée sans scrupule aucun, directement par les patrons et indi-

114. S. VERVAECK, Enkele bronnen uit de Franse Tiga. Hun belang voor de sociale geschiedenis (Quelques sources de la période française. Leur intérêt pour l'histoire sociale). Cahier 22 du Centre Inter-universitaire d'Histoire Contemporaine, Louvain-Paris, 1962, $108 \mathrm{p}$.

115. R. DELBABRB, Enkele bronnen voor de sociale geschiedenis te Gent in de $19^{\circ}$ eeuw, 1794-1914 (Quelques sources pour l'histoire sociale à Gand au XIX ${ }^{\circ}$ siècls), Handelingen $\mathrm{Mij}^{\circ}$ Gesch. en Oudh. Gent, n. s. XVI, 1962, pp. 41-75.

116. K. VAN ISACKER, Meesters en huurlingen. De Staking van 1907 aan de haven van Antwespen. Aniwerpen, 1962, p. 145. - De Antwerpse dokwerker, 1830-1940, Antwerpen, 1963, p. 267. 
rectement par les contremaîtres qui voyaient dans leurs fonctions une possibilité d'étendre et de stimuler leur commerce privé ou leur café.

Au début les socialistes n'eurent pas prise sur le prolétariat illettré et abruti. Une certaine amélioration ne se marqua qu'au début du $\mathrm{Xx}^{\mathrm{e}}$ siècle. Les premiers centres syndicaux dignes de ce nom furent créés par les démocrates chrétiens (tendance Daens). L'activité maladroite et la concurrence croissante d'autres organisations firent tout échouer. A ce moment, les patrons reprirent l'initiative. Afin de parer à l'avenir à toute exigence ouvrière ils créèrent une association pour les ouvriers où ils se réservaient la décision finale.

Des avantages matériels substantiels furent accordés aussitôt. L'existence de cette association devait signifier une garantie pour la paix sociale du port mais supposait aussi une soumission permanente des dockers.

La grève de 1907 n'apporta à cette situation aucun changement réel. L'enjeu n'était pas un conflit de salaire mais l'exigence des socialistes de la reconnaissance du syndicat et de la personnalité humaine des ouvriers. La lutte fut extrêmement dure.

Les socialistes n'eurent à compter que sur eux-mêmes. Les démocrates chrétiens n'eurent pas le courage de persévérer jusqu'à la fin tandis que les associations patronales pouvaient compter sur l'aide effective de l'étranger. Leur slogan était : « nous voulons la soumission pure et simple ».

Pour sortir de cette impasse les socialistes parvinrent à un compromis grâce à la collaboration du bourgmestre Hertogs, qui ne mit pas fin à la suprématie théorique de l'association patronale mais sauva le syndicat socialiste sans perte de prestige.

La suprématie absolue était définitivement rompue. Et, faut-il le dire, la faiblesse des réactions des syndicats chrétiens leur fut amèrement reprochée par les socialistes et il en résulta des luttes internes et un nouvel affaiblissement du mouvement syndical.

La situation s'améliora notablement après la guerre. Malgré l'opposition continue des conservateurs, une coalition socialo-chrétienne parvint à créer un esprit nouveau dans la maison communale et la composition du comité paritaire national pour le port provoqua la création d'un contrat de travail qui apporta finalement la détente attendue depuis si longtemps.

Par son étude consacrée à la vie et à l'œuvre de son père, J. Levie S. J. ${ }^{117}$ apporte une intéressante contribution à l'histoire du mouvement chrétien social dans le bassin de Charleroi. En mettant en relief l'action sociale et politique de Michel Levie comme militant catholique, orateur politique, député de Charleroi (1900-1911, 1918-1921), ministre des finances (1911-1914) et représentant secret du gouvernement belge sous l'occupation allemande (1914-1918) l'auteur nous donne de précieux renseignements sur les situations sociales à Charleroi pendant plus d'un demi-siècle et sur l'histoire et l'activité de quelques institutions importantes telles que le Comité central des

117. J. Levie, S. J., Michel Levie (1851-1939) et le mouvement chrétien social de son temps. Paris-Louvain, éd. Nauwelaerts, 1962, 537 p. (Etuces morales, sociales et juridiques). 
œuvres sociales du Bassin de Charleroi, la Coopérative des Ouvriers Réunis et la Ligue Démocratique belge et sur les efforts accomplis par son père pour l'union des sociétés ouvrières chrétiennes et pour l'autonomie politique ouvrière dans l'union catholique. Un dernier chapitre traite de l'activité d'après-guerre de Michel Levis et de sa collaboration à la restauration nationale par les mandats officiels et les charges publiques qu'il exerça et par les œuvres sociales dont il assuma la direction.

I.e Centre de Recherche et d'Information Socio-Politiques a sélectionné les articles les plus intéressants d'André Renard. La société Imprédi de Liège les a publiés ${ }^{118}$.

La sélection est bien faite : pour chaque période, pour chaque phase de la lutte syndicale et politique on a choisi un ou quelques textes, reflétant le mieux la pensée de leur auteur. Tous ces écrits sont marqués par l'esprit militant de ce «syndicaliste indépendant».

Pour l'histoire de l'action syndicaliste et socialiste, l'histoire du Mouvement Populaire Wallon ou simplement la biographie d'André Renard, ce recueil rendra incontestablement de grands services.

\section{Les hommes d'affaires et les entreprises}

Dans ses deux premiers livres sur André Langrand-Dumonceau, le Professeur Jacquemyns avait esquissé l'édification dynamique d'un énorme empire financier. Dans le troisième tome ${ }^{119}$, il s'arrête à l'analyse des figurants, à l'organisation et aux opérations financières et n'hésite pas à dévoiler les procédés peu avouables employés par son héros. Des politiciens influents et des représentants marquants de la noblesse apparaissent ainsi sous un jour nouveau. Il est étonnant de constater avec combien de naïveté ceux-ci comme ceux-là se laissèrent mener. Bien sûr, la montée en flèche du soi-disant génial financier aveugla son entourage. Mais il sut aussi manœuvrer l'opinion publique avec une grande maîtrise, créant ainsi une ambiance nouvelle autour de lui. Enfin ses largesses, pour ne pas dire ses procédés de corruption firent taire bien des suspicions et bien des critiques. Despote moderne, il gouvernait un état dont il était le seul à connaître la structure. Se passant de conseils d'administration et de conseils de surveillance, il passait des transactions avec lui-même au nom de ses nombreuses firmes. Pas question de système dans tout cela. Il s'agissait plutôt d'une succession de mesures fortuites et non d'un plan bien conçu. L'accumulation de nouveaux organismes avec des capitaux de plus en plus vertigineux furent les écrans qui masquèrent l'impuissance et les échecs des entreprises précédentes. Ses manipulations d'hommes, de capitaux, de titres, de prestige social et de consciences paraissent incroyables. Et pourtant, l'idée même d'organiser le crédit foncier et agricole et de le rendre plus sûr grâce à l'assurance hypothécaire aurait pu réussir. La situation économique et sociale de l'Autriche et de la Hongrie fournissait d'amples

118. André Renard écrivait. Recueil d'articles, 1936-1962, Liège, [1962-63], 343 p.

119. G. JACQUEMYNS, Langrand-Dumonceau promoteur d'une puissance financière catholique. t. III. Vers l'apogée (2. Organisation et opérations). Bruxelles, 1963, pp. 578 (Université libre de Bruxelles, Institut de sociologie). 
possibilités pour des investissements prudents, mais cela ne correspondait pas au type nouveau du financier et au nouveau style qu'André Langrand désirait imposer. Tout fut axé sur une réalisation rapide et sur la grosse réussite. Cette illusion de bien-être et de succès fut entretenue par d'incroyables spéculations boursières, des bilans faussés, des informations inexactes, des transactions inextricables de capitaux réels ou imaginaires. Les risques furent gros. Les sommes considérables avancées à des princes aux titres ronflants, l'achat inconsidéré et le lotissement d'énormes domaines devaient mener tôt ou tard l'entreprise à la ruine. André Langrand mit son point d'honneur dans la réussite de « l'Emprunt pontifical », qui le fit proclamer le fondateur d'une puissance financière catholique. Mais l'entreprise fut un échec qui lui porta un coup mortel. Un quatrième et dernier volume, promis par $\mathbf{M}$. Jacquemyns, nous mènera à la ruine totale et la liquidation des entreprises Langrand-Dumonceau.

Après celui des archives de «Cockerill-Ougrée » $\mathbf{M}^{\text {me }}$ ColleMichel 120 publie maintenant l'inventaire de celles de l'« EspéranceLongdoz », précédé d'un historique de la société, d'une liste des «titres en portefeuille au 30 juin 1960 » et d'une bibliographie sommaire et suivi de très précieux indices de personnes (avec notices biographiques), de lieux et de sociétés.

De son côté, $M^{\text {me }}$ Coppejans-Desmedt à qui on doit déjà une étude sur les statistiques industrielles des années 1795-1846 ${ }^{121}$, édite deux de ces statistiques. Elles sont dues à une initiative privée, celle d'Emmanuel Carolus Van der Meersch et décrivent la situation de l'industrie cotonnière de la Flandre en 1817 et en $1826^{122}$. La situation mobilière (c'està-dire les machines et les bâtiments) la situation matérielle (c'està-dire la quantité et la valeur de la matière employée) la situation manufacturière (c'est-à-dire le prix de la main-d'œuvre et des pièces filées) et l'importance numérique du personnel employé sont successivement mentionnés dans les deux statistiques. Ce simple énoncé permet d'en mesurer toute l'importance et toute la valeur.

Celui qui écrira l'histoire du bassin charbonnier liégeois du $\mathrm{XIX}^{\mathrm{c}}$ siècle, se servira avec profit de la monographie que $M$. Hansotte vient de consacrer au charbonnage du Val Benoit ${ }^{123}$. Après un essai infructueux en 1810, l'affaire démarre en 1826. Le propriétaire du fonds, Lesoinne, s'associe à quatre représentants typiques de l'activité industrielle du pays : Cockerill (métallurgie), Suermondt (finances), David (textile) et Corbesier (houillerie) pour constituer la société civile du Val Benoît. Aidés par une puissante machine d'exhaure de 120 chevaux, les travaux sont bien menés et les bénéfices sont très appréciables. Mais la différence de mentalité est très grande entre Lesoinne et ses quatre

\footnotetext{
120. I1. Colle-Mrchel, Les Archives de la S. A. Métallurgique d'Espérance-Longdoz des origines à nos jours. (Cahiers $\mathrm{n}^{\circ} 24$ du Centre Interuniversitaire d'Histaire Contemporaine), Louvain-Paris, $1962,67 \mathrm{p}$.

121. Ici même, t. 44, 1962, p. 148.

122. H. CoppeJANS-Desmed, De statistieken van Emmanuel Carolus Van der Mecrsch over de Katoenindustrie in Oost-Vlaanderen. Bull. Com. Roy. Hist., t. 128, 1962, pp. 121-181.

123. G. HANSOTTE, Une entreprise charbonnière liégeoise au $X I X^{\circ}$ siècle : le Val Benoit. Contribution à l'histoire $d u$ capitalisme. Annuaire de la commission communale de l'histoire du Pays de Liège, t. 6, 1962, pp. 1263-1287.
} 
associés. Leur esprit de hardiesse et d'entreprise les conduit à inféoder l'affaire à une autre plus importante (la société anonyme des charbonnages et hauts fourneaux de Sclessin) ce qui provoque en 1856 la transformation de la société civile en société anonyme qui à cette date compte trois sièges d'exploitation. La prospérité sera continue jusqu'en 1874. A partir de ce moment, l'entreprise est en déficit constant jusqu'à la date de sa liquidation en 1882. Des difficultés d'exploitation et la crise qui sévit dans la métallurgie expliquent cette situation.

Un autre article dû à $M$. J. Puraye ${ }^{124}$ permet d'améliorer notre connaissance de la mentalité du $\mathrm{xIx}^{\mathrm{e}}$ siècle industriel. Rapidement, peutêtre même hâtivement écrit, ce récit nous conte la vie d'un homme aisé dont le père avait déjà quitté sa Hesbaye natale pour la ville de Liège où un commerce de tabac, de vin et de café ainsi que de bonnes opérations pendant la période révolutionnaire lui permirent de s'enrichir et de laisser un très bel héritage à ses enfants, tel Gilles Antoine Lamarche. Si en 1817, il achète un beau et important domaine rural à Modave, une dizaine d'années plus tard il acquiert, avec ses frères, une fonderie et des terrains à Ougrée. Après 1830, l'entreprise est modernisée et Gilles Antoine Lamarche s'intéresse par surcroît à l'industrie charbonnière. Bientôt la fabrique de fer devient une société anonyme (en 1836) dont les statuts précisent les buts : fabriquer de la fonte, du fer, des machines, extraire du minerai de fer, exploiter du charbon, fondre et laminer le cuivre et le zinc. Si dans le conseil d'administration des banquiers apparaissent et si parmi les commissaires se trouve J. Cockerill, Gilles Antoine Lamarche est directeur gérant. Deux ans plus tard, il devient président du conseil et le restera vingt-cinq ans durant. retenu.

On le voit l'esquisse est sommaire mais l'exemple mérite d'être

M. R. Chambon ${ }^{125}$ retrace la fondation d'une «manufacture de glaces, verres à vitres, cristaux et gobeleteries » et de la "Société de Charleroi pour la fabrication du verre et de la gobeleterie ». La Banque de Bruxelles et surtout la Société générale se sont intéressées à la verrerie depuis les premières années de l'indépendance. Jean Coghen, commissaire de cette dernière société a contribué considérablement à la domination de la verrerie belge par la Société générale et à l'épanouissement de cette industrie.

Regrettons que l'auteur ne mentionne pas ses sources.

M. Arnould ${ }^{126}$ a publié un aperçu de l'histoire contemporaine du Hainaut, bonne synthèse d'histoire régionale qui peut servir d'exemple sur bien des points. Dans le Hainaut, comme ailleurs, la révolution industrielle change profondément les structures sociales et politiques. Mais il faut signaler l'existence d'un radicalisme politique qui déborde largement les cadres du parti socialiste et dont on perçoit l'existence dès la fin de l'Ancien Régime.

124. Gilles Antoine Lamarche 1785-1865. Notes pour servir à l'histoire industrielle du pays de Liège. Bull. Inst. Arch. Liégeois, t. 75, 1962, pp. 101-151.

125. R. Chambon, La verrerie belge en 1836. Industrie, XV, 1961, pp. 774-784.

126. M. A. ARNoul.D, Du Hainaut autrichien à nos jours. Dans l'ouvrage collectif : * Hainaut d'hier et d'aujourd'hui $\gg, 1962$, pp. 141-153. 


\section{Le mouvement flamand}

Pour l'histoire du Mouvement Flamand citons d'abord les livres de $M$. Elias ${ }^{127}$. Deux des quatre volumes prévus ont été publiés en 1963. L'auteur ne vise pas à étudier le Mouvement Flamand proprement dit mais l'évolution de l'idée nationale flamande depuis la Révolution Brabançonne jusqu'à la première guerre mondiale et les diverses justifications qu'on en a données.

C'est pourquoi le premier tome, qui se termine à la Révolution Belge, est consacré à tout ce qui a contribué à l'esprit de solidarité des « Belges ».

L'absence d'un nationalisme «actif » et la politique autrichienne d'abord, française et néerlandaise ensuite, ont suscité des formes négatives et passives de cette solidarité : les « Belges» ont accepté l'unitarisme jacobin et ils ont pris conscience de ne pas avoir les mêmes caractéristiques que les Français ou les Hollandais. Même lorsque la politique d'absorption de la France napoléonienne pénétra profondément les classes dirigeantes, une terminologie «belge » devint d'usage courant pour désigner les neuf départements. L'auteur croit aussi que les divergences idéologiques - apportées par la Révolution Française ont contribué au renforcement de cet esprit de solidarité : du moment que la base des structures d'état, c'est-à-dire de certaines conceptions de l'état libéral-national, n'était plus menacée, ces divergences ont renforcé la vie nationale au lieu de la détériorer.

Le royaume des Pays-Bas se heurte tout de suite à cette prise de conscience "belge », dans laquelle on trouve beaucoup de " traditionalisme », voire de la nostalgie de l'Ancien Régime. Ce traditionalisme d'inspiration religieuse (et même linguistique car l'esprit catholique conservateur en Flandre n'opposait pas seulement le catholique au protestant mais le Flamand au Hollandais), la francisation profonde des provinces belges et l'autocratie de Guillaume $I^{\text {er }}$, provoquèrent la révolte des "anti-Hollandais». La séparation fut pourtant le résultat d'un équilibre intérieur et international, le « parti français » étant assez fort pour la provoquer et la France elle-même trop faible pour accomplir l'annexion.

Le second tome vise plus particulièrement la naissance du mouvement flamand dans la Belgique indépendante, sans perdre de vue les grands courants ou réminiscences de courants idéologiques de l'époque («Aufklärung », romantisme, révolution française : mouvements sociaux de 1848). L'auteur distingue trois groupes de flamingants. $1^{\circ}$ Le groupe de Gand : libéral, d'abord orangiste, ensuite - et surtout pour des raisons de tactique - loyal à la Belgique mais toujours préoccupé de maintenir l'unité culturelle entre la Flandre et la Hollande. $2^{\circ}$ Le groupe d'Anvers : libéral lui aussi ct qui a soutenu la révolution de 1830. $3^{\circ}$ Les traditionalistes, pour qui la défense de la langue flamande

127. H. E. Er.IAs, Geschiedenis van de Vlaamse Gedachte, 1780-1914 (Histoire de l'idée nationale flamande). I. De Grondslagen van de Nieuwe Tijd, 1780-1830 (Les bases d'une ère nouvelle), Antwerpen, 1963, 455 p.; II. Van de taal- en letterkundige hernieuwing naar een politieke beweging, 1830-1859. (D'un renouveau linguistique et littéraire vers un mouvement politique), Antwerpen, 1963, $433 \mathrm{p}$. 
n'était en somme qu'un moyen de protéger le catholicisme. Bien que la presse francophone les ait accusés régulièrement d' " orangisme » ou de « séparatisme », leurs intentions étaient toutes autres. De crainte que la France ne parvienne un jour à réoccuper la Flandre, ils se considéraient comme les meilleurs gardiens de la nationalité et de l'indépendance belges. En majorité ils ont condamné la révolution de 1848 . Pour des motifs sociaux, certes, car ils étaient tous des petits bourgeois, sans compréhension pour le socialisme. Mais aussi à cause de cette horreur de la France, qui leur faisait même passer sous silence les idées conservatrices existant en France.

D'autre part les Flamands ont repoussé 1'idée du Pan Germanisme malgré les initiatives de certains. Sur le plan culturel leurs regards restaient tournés vers le nord sans perdre leur loyauté envers la Belgique.

Il nous est impossible de commenter ici tous les aspects intéressants de ces deux volumes. Leur intérêt ne réside d'ailleurs pas seulement dans l'analyse du sujet (et cette analyse nous semble très détaillée, très approfondie, ayant soin de voir les détails dans un contexte plus général), c'est en même temps un « status questionis » de l'histoire du Mouvement Flamand du point de vue nationaliste. En voilà aussi les limites... mais nous croyons préférable de réserver une critique définitive jusqu'après la parution des volumes III et IV.

I1 convient de mentionner maintenant deux conférences sur l'histoire des relations entre le mouvement socialiste et le mouvement flamand ${ }^{128}$. Le premier texte de $M$. Oukhov, esquisse l'essentiel de la période 1830-1890. Les dirigeants socialistes de cette période ont toujours défendu la cause flamande. Ils ont compris la valeur démocratique de cette lutte mais ils savaient fort bien qu'on ne pouvait demander à des ouvriers analphabètes, dont les besoins vitaux euxmêmes n'étaient pas satisfaits, de s'intéresser à des problèmes linguistiques. D'autre part l'horreur du socialisme chez les flamingants les a empêchés de comprendre la nécessité d'une révision de leurs conceptions sociales. Dans ces conditions une compréhension réciproque devenait de plus en plus impossible.

L'autre conférencier, L. Picard s'est livré à des réflexions personnelles, ce qui ne signifie pas que ses remarques ne soient pas intéressantes, bien au contraire. Mais il faut considérer son texte comme une tentative d'orientation du mouvement, c'est donc plus une source qu'un exposé historique.

Par ailleurs les relations entre mouvement flamand et mouvement pangermaniste (période 1840-1907) ont été étudiées par J. Behets dans plusieurs articles ${ }^{129}$. Ces relations ont d'abord été encouragées par les ministres catholiques belges pour se mettre

128. Socialisme en Vlaamse Beweging (Le socialisme ct lc mouvement flamand), Edition August Vermeylenfonds, 1963, $58 \mathrm{p}$.

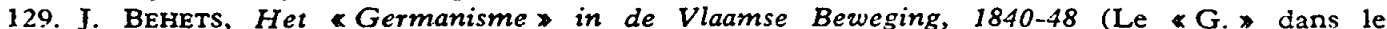
mouvement flamand). Wetenschappelijke Tijdingen, XX, 1960, col. 5-12, 201-210. De Vlaamse Beweging tegenover het Dietslandisme et het Pangermanisme, 1848-1864 (Le M. F. vis-à-vis du mouvement thiois et du P.). Ibid. XXII, 1962, col. 441-458. «Dieis of Duits》? De Vlaamse Beweging onder toenemende pangermanistische druk, 1866-1887. (Le Thiois ou l'Allemand? Pression pangermaniste grandissante). Ibid., XXIII, 1963, col. 211-227. De breuk tussen de Vlaamse Bewegers en de Pangermanisten, 1887-1907 (La Rupture entre M. F. et P.). Ibid., XXIII, 1963, col. 451-464. 
à distance, et à l'abri des tendances annexionistes françaises. Après, l'intensité des contacts et la force des idées pangermanistes furent influencées par les besoins de la politique internationale. La grande majorité des Flamingants pourtant n'a jamais accepté d'identifier sa cause à la cause pangermaniste, les intentions impérialistes des Allemands sautant aux yeux. Mais ils n'ont jamais refusé non plus de maintenir des rapports culturels.

\section{La presse}

En ce qui concerne l'histoire de la presse il faut signaler trois cahiers intéressants du centre interuniversitaire d'histoire contemporaine, dont deux ont été élaborés suivant une méthode identique.

M. L. Wils ${ }^{130}$ étudie un certain nombre de journaux anversois des années 1857-1864 parce que cette période marque un tournant décisif dans l'histoire politique de la ville. L'auteur a préféré l'étude chronologique à l'étude systématique pour maintenir un contact étroit avec le mouvement politique. Quatre journaux libéraux paraissaient en 1857. "Le Précurseur » qui occupait depuis longtemps une place prépondérante fut racheté tout comme "De Schelde » par Outendirck qui était déjà propriétaire de "l'Avenir ». Ce trust se mit entièrement à la disposition du gouvernement Rogier mais négligea les intérêts anversois et perdit, par là même, la sympathie de la population. Dans l'association libérale, où l'esprit unioniste n'était pas définitivement enterré, on refusa de suivre cette voie et la réplique vint sous la forme d'un nouveau journal "L'union commerciale ». Le projet d'Outendirck de monopoliser toute la presse anversoise échoua donc et il fit faillite en 1860 .

Deux journaux reconquirent leur indépendance mais « De Schelde » ne survécut pas.

La formation du parti "Meeting 》 en décembre 1862 exigea des journaux une nouvelle déclaration de principe. L'opposition attaqua par la fondation du "De Koophandel », qui provoqua à son tour la naissance de « 1'Escaut».

L'auteur met l'accent sur les fortes traditions unionistes qui survécurent et sur l'orientation radicale des journaux d'expression flamande. Il croit pouvoir expliquer leur caractère progressiste par l'intérêt que le public porte à une politique plus sociale et par le fait que la nouvelle direction de l'action flamande a été suivie par les rédacteurs de ces journaux.

De son côté, J. Lory ${ }^{131}$ nous présente tous les renseignements qu'il a rassemblés sur la presse belge au cours de ses recherches sur «les réactions belges devant la question romaine en 1870-1871». L'auteur traite successivement des journaux bruxellois, des revues, des journaux de province et des journaux socialistes, et porte surtout son attention sur la presse bruxelloise. On ne peut que le féliciter des por-

\footnotetext{
130. L. Wr.s, De liberale Antwerpse dagbladen, 1857-1864, Louvain-Paris, 1962, 59 p. (Centre Interuniversitaire d'Histoire Contempora:ne, Cahier $\mathrm{n}^{\circ} 26$ ).

131. J. LORY, Panorama de la presse belge en 1870-1871 Louvain-Paris, 1963, 39 p. (Cintre Interuniversitaire d'Histoire Contemporaine, Cahier $\mathbf{n}^{\circ}{ }^{32}$ ).
} 
traits très précieux de « l'Indépendance Belge », de « l'Echo du Parlement », du « Journal de Bruxelles ». Mais la priorité qu'il donne à Bruxelles, en soi tout à fait compréhensible, explique qu'un certain déséquilibre se dégage de son étude.

M. De Vroede ${ }^{132}$ continue infatigablement sa production scientifique avec un répertoire de la presse dans le Limbourg belge de 1830 à 1860. Quatre communes seulement entrent en ligne, dont une (Peer) trc̀s subsidiairement; les trois autres étant Hasselt, Tongres et SaintTrond. Pour chaque journal l'auteur donne toutes les données utiles : date du début et de la fin, titre, format, prix, périodicité, tirage, motto, éditeur et imprimeur, rédaction, puis il esquisse l'évolution et précise les traits typiques de chaque journal et en publie des extraits caractéristiques. La presse limbourgeoise semble avoir été, mises à part quelques entreprises privées, une presse d'opinion et de caractère politiques. A partir de 1857 on peut très bien discerner les tendances de gauche et de droite. La majorité de la presse était catholique ; cinq journaux étaient libéraux, deux progressistes. En général, elle était fort conservatrice et n'atteignait que les classes aisées et moyennes. Après 1860 l'emploi du flamand devient prépondérant. Plusieurs graphiques donnent une bonne image de la durée, de la périodicité et de la couleur politique des journaux.

\section{L'expansion coloniale}

Dans un livre fort bien documenté J. Stengers ${ }^{133}$, professeur à 1'U.L.B., a étudié la genèse de la loi du 18 octobre 1908 qui régla l'organisation du Congo et qui fut pendant un demi-siècle la base du gouvernement belge d'outre-mer. C'est essentiellement l'origine du système d'organisation des pouvoirs, telle qu'elle figure dans cette « charte coloniale » qui a retenu l'attention de l'auteur, qui explique aussi la grande différence qui existe entre le projet de 1901 et le texte définitif de 1908 en exposant le rôle de la Commission des XVII et celui du roi Léopold II. Il conclut qu'un petit nombre d'hommes seulement, qui n'étaient pas du tout des spécialistes des choses congolaises, ont été mêlés activement à l'élaboration de la loi et que les législateurs voulaient un système de contrôle dans le but de juguler les tendances absolutistes du roi.

Le professeur Stengers ${ }^{134}$ expose ailleurs les causes de la fixation des frontières du Congo par Léopold II et montre que le roi songeait au début à l'Afrique centrale tout entière (c'est-à-dire de l'Atlantique à l'Océan Indien) comme territoire du Congo. Ce n'est qu'à la suite de la perte du Nairi-Kwilou que le roi a annexé comme compensation le Katanga. Il traite aussi de la reconnaissance du nouvel état par l'Angleterre, la France, l'Allemagne et d'autres puissances.

132. M. De VROEde, De Belgisch-Limburgse Pers van 1830 tot 1860, Cahiers du Centre Interuniversitaire d'Histoire Contemporaine, $n^{\circ}$ 28, Louvain-Paris, 1963, 226 p.

133. J. Strngras, Belgique et Congo : l'Elaboration de la Charte coloniale. Bruxelles.

134. J. Strngras, Léopold II et la fixation des frontières du Congo. Le Flambeau, XIVI, 1963, 3-4, pp. 153-197. 
Dans une petite communication A. de Selliers de Moranville ${ }^{135}$ nous présente une collection de lettres et de notes échangées entre Léopold II et le colonel Strauch (le collaborateur le plus actif et le plus intime du roi pendant de longues années), collection que le Musée de la Dynastie a pu acquérir.

\section{Les guerres}

L'histoire militaire belge a la chance de tenter non seulement des généraux pensionnés, mais également des historiens de valeur, tel le professeur J. Verbruggen, le colonel Ch. Brusten, MM. E. Wanty, G. Hautecler, Leconte (père et fils) et $A$. Duchesne. Ce dernier, travaillant parmi les sources mêmes de sa spécialité (il est attaché au Musée de l'Armée), vient de publier en 1961 et 1962 une série d'articles où il nous peint l'armée belge de 1871 à 1920 à travers les lunettes des attachés militaires français en Belgique ${ }^{136}$. L'exposé est largement basé sur les Archives militaires de Vincennes, comprenant les rapports des douze titulaires successifs du $2^{\circ}$ Bureau de l'Etat-Major Général de l'Armée française. Ces rapports confidentiels si volumineux nous rapportent l'opinion que les délégués se faisaient de notre appareil militaire et ce qu'ils savaient du problème de la neutralité belge dans le conflit franco-allemand, des lignes de défense (Anvers, la Meuse), et de la question du service personnel obligatoire. Dans la dernière partie l'auteur aborde la période et le problème les plus importants des relations franco-belges, la première guerre mondiale et ses suites immédiates. Un des aspects qui a beaucoup préoccupé les milieux militaires français est la question flamande, aussi bien du point de vue militaire (l'attaché militaire de 1918 est persuadé du patriotisme de la grande majorité des Flamands), que sur le plan général. Des rapprochements culturels furent tentés et après la guerre, à la demande du roi Albert, P. Fredericq occupa une chaire de littérature flamande spécialement créée au Collège de France. Les discussions sur le plan du statut territorial ont abouti à l'accord militaire franco-belge de septembre 1920.

M. E. Wanty, bien connu par son travail sur l'armée belge entre 1830 et $1914^{137}$, étudie les événements du début de la deuxième guerre mondiale, notamment du 10 mai $1940^{138}$. Ce fut une journée tragique pour l'armée belge, avec la prise facile du fort d'Eben-Emael et la conquête des ponts du Canal Albert, avant que l'ordre de destruction n'ait été donné. Comment expliquer ces succès allemands si étonnants? M. Wanty croit que des facteurs de surprise ont joué : le lancement de parachutistes ennemis au milieu des unités belges et l'utilisation de planeurs notamment. Nos dirigeants militaires n'avaient prévu qu'une

135. A. Seliters de Moranvilie, Un Fonds d'Archives nouveau pour l'Histoire du Congo. Bulletin de l'Académie royale des Sciences d'Outre-Mer, 1963, 2, pp. 308-324.

136. A. DUCHESNE, L'armée et la politique militaire belge de 1871 à 1920 jugées par les Attachés militaires de France à Bruxelles. R. B. P. H., XXXIX, 1961, pp. 391-430, 1092-1126; $\mathrm{XL}, 1962$, pp. 371-384, 1188-1219.

137. Voir ici même, t. 41,1959 , p. 97.

138. E. WANTY, Le 10 mai 1940 devant Maestricht : la journée des ponts. Revue Générale Belge, XCVIII, 1962, pp. 17-43. 
guerre défensive, et cultivaient un esprit de défense voire de passivité. L'intérêt de cette contribution réside dans la multitude de faits concrets, ordonnés soigneusement dans plusieurs chapitres. Le plan est très original. D'abord « le problème vu par les Allemands », puis le dispositif hollandais, le dispositif belge, l'action contre Eben-Emael, l'action contre les ponts du Canal Albert, l'action dans le Limbourg hollandais, les réactions belges et la destruction du pont de Briegden (près Veldwezelt). L'auteur note qu'au cours de la nuit du 10 au 11 mai aucune mesure positive n'a été prise pour organiser un service de renseignements ou reprendre du terrain perdu. Rien que des mesures conservatoires et passives.

Un des faits les plus importants de la campagne de mai 1940 fut l'offensive des Panzers de Guderian. En 1962, une version française du livre de $\mathbf{H}$. Guderian a paru. L'officier allemand lui-même nous fait part de ses souvenirs de guerre. C'est un livre de première valeur pour l'histoire de la guerre dans la région des Ardennes et de la Meuse et pour les combats près de Bouillon ${ }^{139}$.

Le commandant G. Hautecler ${ }^{140}$ traite de l'épisode de la bataille de la Meuse en utilisant les archives personnelles du maréchal Rommel. Dans cette bataille, Rommel s'oppose à l'armée française Corap. Les chasseurs ardennais belges eux se replient jusqu'à l'Ourthe, que Rommel parvient à franchir le 11 mai déjà. Afin de contrecarrer l'organisation des Français, Rommel essaye de passer au delà de la Meuse. Le 15 mai ses chars lourds le font près de Bouvignes. Rommel perce définitivement le front de l'armée Corap et peut continuer sans obstacles jusqu'à Avesnes et Arras. Avec la prise de Sedan, c'est une des actions les plus décisives de la campagne de 1940.

C'est la même bataille de la Meuse qui retient l'attention du lieutenant-colonel Legoyet ${ }^{141}$. Il s'agit de points de détails et d'opérations qui ont eu lieu à Anhée et Vireux.

Dans la revue La Vie Wallonne, L. Papeleux attire notre attention sur un aspect de la deuxième guerre mondiale, la deuxième bataille des Ardennes de 1944-45, la fameuse contre-offensive Von Rundstedt ${ }^{142}$. Il y traite jour par jour des événements les plus frappants des mois de décembre 1944 et janvier 1945. Un article de seconde main, s'inspirant de l'ouvrage du journaliste américain J. Toland (Bastogne, La dernière offensive d'Hitler, Paris, 1962). Donc rien de neuf.

\section{L'histoire locale}

Dans le domaine de l'histoire locale, il faut signaler une initiative intéressante du Crédit Communal de Belgique. Il a demandé à cinq spécialistes de l'histoire locale, $M^{11 \mathrm{e}}$ Bruwier, MM. Arnould, Dhondt,

139. H. Guderian, $A$ la tête des Panzers, Souvenirs d'un Soldat. Paris, 1962, 446 p. L'édition anglaise : Panzer Leader, London, 1952.

140. G. Hautecler, la bataille de la Meuse (12-15 mai 1940), Rommel contre Corap. Revue Belge Générale, XCVIII, 1962, pp. 93-103.

141. Lt.-Col. LegoYet, Le 11० Corps d'Armée dans la bataille de la Meuse 10-15 mai 1940, Revue Hist. Armée, 1961, n ${ }^{\circ} 1$, pp. 125-138; n 2, pp. 83-95.

142. L. Papeleux, La deuxième bataille des Ardennes (décembre 1944-janvier 1945) : La Vie Wallonne, XXXVI, 1962, pp. 129-35. 
Rousseau et Vercauteren, de rédiger un petit vade mecum « Les travaux d'histoire locale, conseils aux auteurs » (Bruxelles, Pro Civitate, 1962), où sont données des indications concrètes portant sur les problèmes, le mode de rédaction, les sources et les répertoires.

Sous les auspices de l'administration communale de Tamines, $M$. Jean Fichefet docteur en géographie - dont les historiens connaissent déjà l'Etude de Géographie urbaine sur Charleroi - vient de publier une Nouvelle Histoire de Tamines ${ }^{143}$. Cet ouvrage rend en effet un son très neuf; il est incontestablement la meilleure monographie locale parue depuis longtemps en Belgique.

Soulignons d'abord qu'il répond à toutes les exigences scientifiques, ce qui n'est malheureusement pas courant dans ce genre d'études. De plus, son optique est excellente. $M$. Fichefet va à l'essentiel; il envisage tous les points de vue à partir de la vie quotidienne des habitants de Tamines et traite aussi bien des moyens de communication que de la création des écoles et de l'évolution démographique. On aurait aimé y trouver une conclusion générale où auraient été ramassés les phénomènes cruciaux de l'histoire de cette grosse commune, ceux qui la dominent et l'expliquent. Car il en est de l'histoire des communautés comme de celles des personnes, quelques clefs suffisent pour comprendre.

Le deuxième volume du catalogue de l'exposition «Anvers 18601960 » (octobre-novembre 1960), vient de paraître ${ }^{144}$. Le premier volume contenait une documentation abondante sur les élections, la banlieue, la population, les monuments, toutes les institutions, le port, etc. Mais tout ce qu'on avait espéré y insérer n'y était point. C'est pourquoi un deuxième volume était nécessaire. Outre des corrections au premier tome on y trouve un aperçu historique des institutions communales et une bibliographie des livres et périodiques de la bibliothèque de la ville concernant ce qui a été publié sur Anvers, à Anvers et par des Anversois.

Espérons que cet exemple servira de modèle à d'autres villes. L'histoire locale en profitera.

143. Jean Fichepet, Nouvelle Histoire de Tamines. Etude historique, économique et sociale, 